\title{
Experimental Study of Distortion in Butt Welds of Mild Steel Plates and En-31 Plates Having Different Thickness and Weld Cross Sections
}

\author{
Abhishek Singh Gangwar ${ }^{1}$, Anurag Srivastava ${ }^{2}$, Neha Gupta ${ }^{3}$, Rajan $^{4}$ \\ ${ }^{I}$ (Mechanical, SRIMT, India) \\ ${ }^{2}$ (Mechanical, SRIMT, India) \\ ${ }^{3}$ (Mechanical, BBDNITM, India) \\ ${ }^{4}$ (Mechanical, GITM, India)
}

\begin{abstract}
Welding is a process for joining different materials with the help of number of process in which heat is supplied either electrically or by means of a gas torch. Pressure may also be employed, but this is not, in many processes essential. Welding is an important process for fabrication of engineering components. It has wide applications in ship buildings, constructions, aerospace, automobile industries, etc. There are some welding defects due to which weldments fails under service conditions and cause damage to the property and loss of human lives. In this work we are going to study one of the welding defects known as Distortion. Distortion is the change in shape and difference between the positions of the two plates before welding and after welding. Distortion occurs due to good amount of temperature difference at various points along the joint and thus at any instant certain area of base metal expands and other including weld bead contract. In this paper we are going to study how much distortion occur in low carbon steel and medium carbon steel that is Mild Steel Plates and EN-31 Plates of various cross-sections and thickness. This study is down by experimentally rather than by using any software, so that we can get more effective data.
\end{abstract}

Keywords: Low carbon steel, medium carbon steel, mild steel plates, EN-31Plates, Distortion, Butt welding

\section{Introduction}

The term distortion means deviation from desired or actual shape and size. In welding terminology distortion means the local residual deformation resulting from welding which changes the dimension and shape of the work-piece joined.

Once upon a time when the welding operator used shield and electrode holder and commenced welding a job, starting and finishing at any place. After completion of the job if it was found distorted and it was taken for granted that it could not be avoided. The impression was all welding caused distortion. So why think of it. This was purely ignorance, because distortion can be controlled and minimized by approaching the job in the correct manner.

At present, welding can be done with minimum distortion. For example, large machines beds are being fabricated out of rolled steel sections and plates can be welded within a tolerance of $1.5 \mathrm{~mm}$. The most important factors in the production of a successful and economical weldment or broken part repair is the minimization of distortion. Excessive distortion increase the job cost due to expense of rectification or may cause the careless of the job. Thus welding deformation not only complicates the fabrication of welded structure but also reduces its fitness for the job for which it is designed. Moreover in welding causes locked up stress or residual stress in the weld zone which on one hand contributes to weld cracking and on the other hand it is suspected to have an important effect on the brittle fracture of the welded structures. This may also reduce the load carrying capacity of the member. Hence the prediction of distortion and its thorough analysis is called for.

\section{Effect of distortion}

It is noted that heat does not occur uniformly on a work piece while welding process is carried on. For that reason a local residual stress (thermal stress) has been developed on that work piece due to shrinkage of weld distortion. Hence distortion is an after effect of fusion welding and it results change in dimensions and shape of assembled parts compared to what these were before welding. So it is clear that the measurement of any job was to the design specification before welding is not same afterwards.

This deviation may happen in the complicate parts of the fabrication of welded structures but may often reduce the matching of the finished structures for the purpose for which it was designed. For an example, we have seen that while a job being welded, it gets deformed (afterwards), which is not matching in original one. So it would first have to be straightened. But even after restoring the shape its dimension must not be the original one. For corrected result, but cutting off the excess material from it or by adding some suitable length of it, this 
is laborious and time taken for completion of the job. For greater complication can be arise, if a joint were to be made between the longitudinal edges of two members with different dimensions and consequently suffering different deformations. So, it is clear for getting higher dimensional accuracy and trueness to shape is needed the cost rectifying the job sometimes become higher than that of actual assembly welding.

Reduction of effectiveness cross-section due to local warping may results in stresses higher than the actual value. Due to welding on a job its gets deformation hence it reduces accuracy and fitness for which they were designed. For instance in a long straight member, additional bending moment has been developed at the time of loading, which is not taken into account at the time of design calculations. In- some cases welded seams does not carry loads or equal loads which is due to local building of butting units. This happens over stressing of individual seams. So, it is clear that due to deformation of welding the work piece loses its originality from welded structure or the effective cross-section is reduced whilst maintaining its calculated shape.

\section{Causes of distortion}

Distortion in weldment is caused by stresses that are induced in the weldment by non-uniform expansion and contraction of both the weld metal and the adjoining base material. The major factors affecting this are the temperature of weld area (Heat input), yield strength of the material, coefficient of thermal expansion and thermal conductivity, the material transformation that occurs in the cycle from solid to molten. Hence to predict distortion critical analyses of different factors are of vital importance.

\subsection{Effect of Heat Input}

As we know, if a pieces of metal is heated uniformly from room temperature then it can expand in any directions, when it is cooled down, its dimensions, comes to the original dimension. But if it is not heated uniformly or freedom of movement is restrained, the final dimensions will not be the same. In welding when we are striking an arc then most of the base metal is cold, but as the welding proceeds, heat from the welding area dissipates through the plates causing expansion. At the same time as the molten weld freezes and tends to contract, expansion and contraction, therefore occurs at the same time and it continued to the plates being welded, the forces set up produce a complex stress system. As the further welding is taking place in the same area, the stress field becomes more and more complicated. The degree of localization of heat input is another important aspect as far as distortion is concerned. More the concentration of heat input lesser will be the distortion.

\subsection{Inherent Stresses in the Parent Metal}

Condition of the parent metal before welding also has an effect on distortion. Stresses are set up at plates and bars as a result of performing, gas cutting, rolling and shearing. Rolled section like angles beams, channels tend to be stress relieved when welding heat is applied. This can cause such members to distort in a manner which can't be solely attributed to welding.

Particularly for rolled sections it is extremely difficult to anticipate how they will react to the welding heat since the pattern of the internal stress is unknown and it is often found that one length of the section behaves in an entirely different manner from another length of the same section.

For plates and Bars situation is same what better due to the fact that forming work has done i.e. cause of the stress is known. Hence the behavior of the material can be anticipated to some extent. For example a plate which has been rolled to a curved shape will tend to straighten when the rolling stresses are relieved locally by the welding heat.

Sometimes these parent metal stresses will oppose the distortion caused by welding and thus reduces the resultant distortion. Sometimes it will have an opposite effect. So it is advisable, items containing inherent stress, the measure to minimize their movement during welding should be taken

\subsection{Joint Restraint}

During welding the degree of joint restraint imposed in a considerable bearing on the amount of distortion. The least distortion is taking place where little movement of the parent metal can take place but the greatest distortion occurs when the parent material is free to follow the shrinkage movement of the weld. During cooling the degree of restraint is increased parent metal becomes increasingly stressed until yield point is reached. Yielding will than occur and continue to get and equilibrium, This cause cracking of the weld and high internal Stress Restraint as a means of controlling distortion must, therefore, be used judiciously. 


\subsection{Thermal Properties}

\section{a) Coefficient of Expansion}

Higher coefficient of thermal expansion means higher amount of expansion, when heated and greater subsequent contraction when cooled. High coefficient of thermal expansion tends to increase the shrinkage of the weld metal and the metal adjacent to the weld. Thus increases distortion.

b) Thermal Conductivity

Thermal conductivity in a measure of heat flow, lower the thermal conductivity steeper the temperature gradient. Hence increases distortion.

\section{c) Yield Point of the Material}

Higher the yield point of material in the weld area, greater will be the residual stress that can act to distort the weld assembly. Conversely, lower the yield point, less severe the possible distortion. The nature of change of yield point with temperature also affects the magnitude of distortion.

Thermal properties also depend upon temperature since at high temperature metallurgical structure changes, naturally physical properties also different from that at room temperature.

Moreover stress strain relationship at the elevated temperatures deviated considerably from the idealized elastic plastic relationship at room temperature. The coefficient of linear expansion decreases to zero in the range between $1200-1500^{\circ} \mathrm{F}$ and then increases again to the high value. This is due to the change in the phase of steel at these temperatures.

The temperature is dependent on coefficient of thermal expansion. On the other hand variation of thermal conductivity with temperature shows almost constancy. On the other hand young's modulus has an almost linear decrease from room temperature to $1000^{\circ} \mathrm{F}$. From the trend we can easily conclude young's modulus reaches to zero value in the range $1500^{\circ} \mathrm{F}-2000^{\circ} \mathrm{F}$. Yield point is defined in all eases by $0.1 \%$ of sett. The zero value of yield point is approximately at $1500^{\circ} \mathrm{F}$.

\subsection{Classification of distortion and its analysis}

Welding Distortion can be classified into following group:

1. Longitudinal shrinkage

2. Transverse shrinkage

3. Angular distortion

4. Bowing

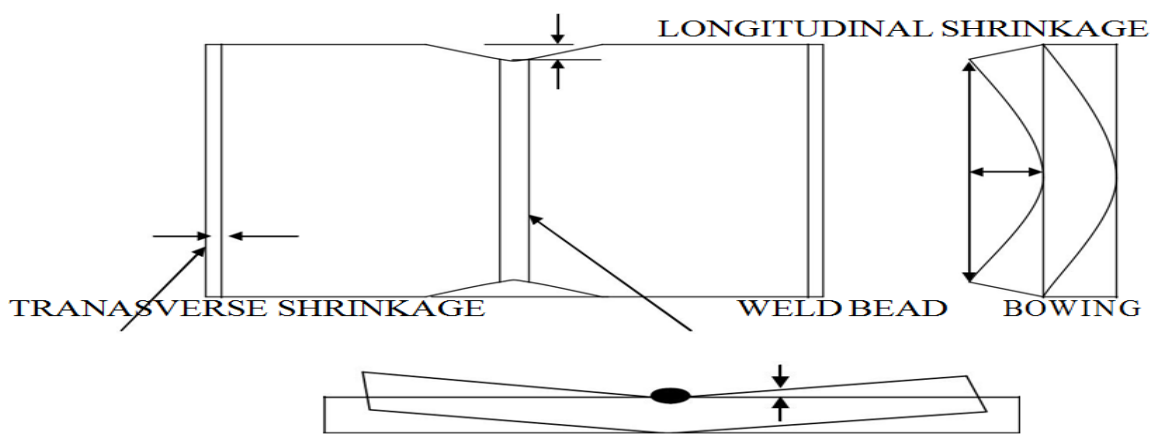

ANGULARDISTORTION

Fig.-1.1 Figure of Type of distortion in welding of free plates

\subsubsection{Longitudinal shrinkage}

When the length of the welded plate is shortened along the longitudinal axis or weld shrinkage parallel to the weld, then it is called as longitudinal shrinkage. When a weld is deposited lengthwise on a light narrow and perfectly flat strip of metal that is neither compiled nor held in any way, the strip will tend to bow upward in the direction of the head. This is occurring due to the longitudinal contraction of the weld metal as it cools. The value of longitudinal contraction is maximum along the weld centre line and decreases towards the edges. Minimum distortion occurs due to High current and large size electrode. Also low current with small size electrode causes minimum distortion. But maximum distortion occur in-between these two situations.

\section{Longitudinal Distortion Depends Upon}

i) Contraction forces.

ii) Distance between the centroids of weld and section.

iii) Stiffness of the section being welded. 


\subsubsection{Transverse shrinkage}

When two plates being butt welded together are neither too heavy nor held together, and are thus free to move, they will be drawn closer together by the contraction of the weld metal. This is called transverse contraction. Transverse contraction exists all along the weld length and it depends upon the permanent contraction of elements in the weld zone. On the other hand when the welded plate is shortened in a direction transverse to the bend then it is called as transverse shrinkage shown in Fig. (1.1). Transverse contraction exists all along the weld length and it depends upon the contraction of elements in the welded zone.

Following Points can be used for Prevented the Transverse Contraction

i) Proper tack welding,

ii) Wedge placing between the plates,

iii) Scarpereding the plates (before welding) to provide allowance (about 1/100mm. of weld) for contraction,

iv) Increasing the arc travel speed.

To analyse the shrinkage mechanism, let us consider the heating of a material held between two immovable faces upon heating the material would try to expand to a new length.

Where,

$\Delta \mathbf{L}$ is the product of coefficient of linear expansion, temperature difference and initial length.

But as it cannot lengthen, it must up set by an amount represented by $\mathrm{L}$ on cooling it shrinks to a dimension $(\mathrm{L}-\Delta \mathbf{L})$ approx. The expansion on heating is given by

$$
\Delta L=\alpha\left(T_{2}-T_{1}\right) L
$$

Where,

$\boldsymbol{\alpha}=$ Coefficient of linear expansion

$\mathbf{L}=$ Initial length

$\mathbf{T}_{\mathbf{2}}=$ Final temperature

$\mathbf{T}_{\mathbf{1}}=$ Initial temperature.

A weld upon cooling in a real structure however is not rigidly restrained but is shrinking against an elastic structure. Further the surrounding material has expanded against the weld and also shrinking.

\subsubsection{Angular distortion}

When two bevelled plates are welded, it is found that the plates are pulled out of line with each other. Since the opening at the top of the single Vee groove is greater than at the bottom, a greater portion of the weld metal is deposited there, and thus the drawing or pulling is greatest on that side of the joint. Angular contraction is related to the shape and size of the cooling weld metal zone and the stiffness of the remaining unused part. Double groove joints tend to minimize angular distortion because the contraction effects of the two sides, i.e., top and bottom of the plate, get cancelled with each other.

\subsubsection{Bowing distortion}

Bowing is bending of weld structures along the length of the weld. This type of distortion is also called longitudinal distortion. Hence after welding the plate takes the shape of a bow as show in Fig. 1.1 i.e. when the longitudinal shrinkage does not occur along the neutral axis of the member it causes bowing.

This is a result of non-uniform shrinkage through the thickness of the plate (i.e. due to difference in shrinkage on the face side and the root side of the plate).

Bowing also depends upon the location of horizontal neutral axis and the location of the weld lead with respect to horizontal neutral axis id the case of welded built up section.

\subsection{Methods to reduce distortion \\ Methods to reduce distortion are as follows}

1) Correct design, size of the weld and edge preparation.

2) The component parts of fabrication must be accurately manufactured to the required shape and size.

3) Use of Pre-setting methods.

4) Use of Restraining Methods,

a) Strong back

b) Jigs and fixture

c) Flexible clamps

d) Back to back assembly

e) Temporary bracing 
f) Stiffening

g) Tack welding.

5) Use of welding sequences and techniques.

a) Skip welding

b) Back-step technique

6) Use of minimum amount of weld metal to satisfy the welding requirements.

7) Force balance.

8) Balance of welding about neutral axis of the fabrication.

9) Balance of weld around the centre of gravity.

10) Reduction in number of passes.

11) Use of intermittent weld where ever possible.

12) Use of shrinkage allowances.

13) Make shrinkage force to work in the desired direction.

\subsection{Distortion correction}

It is not always possible to control distortion within acceptable limits, especially when dealing for first time with a new design of fabrication. There are bound to be instances where, inspire of the most careful planning the distortion becomes excessive. In such cases it is usually possible to rectify the trouble by one of the following methods.

1. Distortion correction by using mechanical means.

a) Hammering

b) Use screw jack and Press.

2. Clamping to a heavy base plate during not only in welding but also during further processing like stress relieving.

3. Localized Heating.

a) Spot heating

b) Localized heating zone.

4. Differential heating to a predetermined temperature.

\section{Literature Survey}

Tsai C.L. et al (1999) [1], had studied welding thin-plate panel structures often results in warping of the panels. Several mitigation methods, including preheating and pre stressing the plates during assembly, have been used. This paper studies the distortion mechanisms and the effect of welding sequence on panel distortion. In this study, distortion behaviours, including local plate bending and buckling as well as global girder bending, were investigated using the finite element method. It was found that during the welding assembly of a panel structure a skin plate of normal thickness (e.g., >1.6 mm) can only buckle when the panel bends globally to cause a large curvature in the skin plate. The structural weight and bending of the stiffeners result in the global panel bending. Weld shrinkage in the $\mathrm{T}$ joints causes angular distortion in the skin plate. Locating welds closer to the neutral axes of the panel cross sections can control the global bending and minimize welding distortion of a stiffened panel. Other mitigation methods include using heavier stiffeners to increase the moment of inertia of the cross section or the eggcrate fabrication method to drastically improve the bending resistance of the panel structure. Using the optimum welding sequence can improve the flatness of the panel and minimize angular distortion in the skin plate. The joint rigidity method is effective in determining the optimum welding sequence for minimum angular distortion in the skin plate of stiffened panel structures.

Huang T.D et al (2003) [2], had investigated residual stress and distortion in lightweight ship panel structures. They found that the nature of the distortions and the key factors contributing to buckle distortions. They founded that:- Local buckling is the dominant distortion mechanism in lightweight panel structures. Dimensional accuracy in thermal cutting has a significant effect on buckling distortion, particularly for different thickness combination, such as insert plates in complex panels. Over welding of butt joint used to fabricate complex panels with thickness transition (inserts) resulted in significant buckling distortion. Therefore, butt-welding plates to make panels require a low-heat-input narrow-groove process to minimize distortion prior to fillet welding of stiffeners. Optimal welding assembly procedures should be sought to maximize the buckling strength. Any effective mitigation techniques for minimizing buckling distortion should either reduce the primary force that drives buckling (e.g., fabrication induced stresses) or increase the buckling resistance.

Murugan V. Vel and Gunaraj V. (2005) [3], had studied effect of process parameters on angular distortion of gas metal arc welded structural steel plates. This angular distortion is mainly due to non uniform transverse shrinkage along the depth of the plates welded. Restriction of this distortion can be reduced by providing initial angular distortion in the negative direction if the magnitude of angular distortion is predictable. It is difficult to obtain a complete analytical solution to predict angular distortion that may be reliable over a wide range of 
processes, materials, and process control parameters. In this study, the statistical method of three-factors, fivelevels factorial central composite rotatable design has been used to develop mathematical models to correlate angular distortion with multipass GMAW process parameters.

They founded that:-

- The second-order quadratic mathematical models are useful in predicting angular distortion of multipass welds.

- Out of the three process variables selected for investigation, the number of passes $(\mathrm{N})$ had a strong effect on angular distortion (a). The value of "a" is about $4.5 \mathrm{deg}$ when other parameters are at lower limits, and it is about 3.1 deg when other parameters are at higher levels.

- The increasing trend of the angular distortion with the increase in number of passes has to be considered carefully in practice to control angular distortion.

- The process parameters, namely, time between successive passes and wire feed rate, have a negative effect on angular distortion.

Deng Dean (2009) [4], had investigated the effects of solid-state phase transformation on welding residual stress and distortion in low carbon and medium carbon steels. For this ABAQUS code, a sequentially coupled thermal, metallurgical, mechanical 3-D finite element model is developed. 3-D finite element model considering phase transformation is develop to analyse the tungsten inert gas arc welding process and to simulate the residual stress and the welding distortion.

He has concluded that:-

- For low carbon steel, phase transformation has an insignificant effect on the welding residual stress and the distortion because of a small dilation due to martensitic transformation and a relatively high transformation temperature range.

- For medium carbon steel, phase transformation has a significant effect on the welding residual stress and the distortion because of a relatively large dilation and a low transformation temperature. In this study, it is observed that a compressive stress in the welding direction is produced in the FZ.

According to the observed results, when the residual stresses and the welding deformation of medium carbon steel are predicted using numerical simulation, it is necessary to consider solid-state phase transformation. On the other hand, the solid-state phase transformation can be neglected for low carbon steel. Neglecting the phase transformation in low carbon steel weld structure will make the numerical model simple and reduce the computation time.

Estefen S.F. et al (2009) [5], had studied surface residual stress evaluation for double-electrode welding. The stresses were monitored after each operational step i.e. positioning, implementing of constraints, welding and constraints removal. The measurements were performed at the deposited metal, heat affected zone, base metal close to the weld joint and along the plate using the X-ray diffraction method. It was observed differences in the stress evaluations for double-electrode welding which resulted in lower bending distortions and higher values of surface residual stresses, compared with single-electrode welding. For the double-electrode case the initial distribution of maximum welding stress values in both HAZ and base metal close to the fillet, while for the single-electrode case the maximum welding stress values were located along the deposited metal. Similar trends were observed in the double-electrode welding. The welding stress evaluation after the constraints removal in the double-electrode case is in different shape from those obtained for the single-electrode welding. For the single-electrode case the residual stress distribution is a result of the stress redistribution on the deposited metal. For the double-electrode case, the stress reduction in the base metal close to fillet results in increasing of stresses on weld metal in the longitudinal direction. For the double-electrode welded plates the longitudinal residual stresses in the deposited metal remain close to zero only until constraints removal, after that they become compatible with the stress values for the single-electrode case.

Deng De-An (2010) [6], had studied theoretical prediction of welding distortion in large and complex structures. In this study, a two-step computational approach, which is a combination of a thermo elastic-plastic finite element method (FEM) and an elastic finite element with consideration for large deformation, is developed to estimate welding distortion for large and complex welded structures. He founded that:-

- By comparing the simulation results of Models I and II with the measurements, the effectiveness of the twostep computational approach has been verified.

- Both numerical results and experimental data of Model II suggest that twisting deformation is a significant feature in the asymmetrical curved block.

- In Model III, because the thickness of the skin plate is small (only $5 \mathrm{~mm}$ ), the buckling distortion is bound to occur after welding. Simulation results suggest that through reducing heat input, using the single-sided welding procedure, and adopting appropriate welding sequence the final welding distortion can be effectively controlled. 


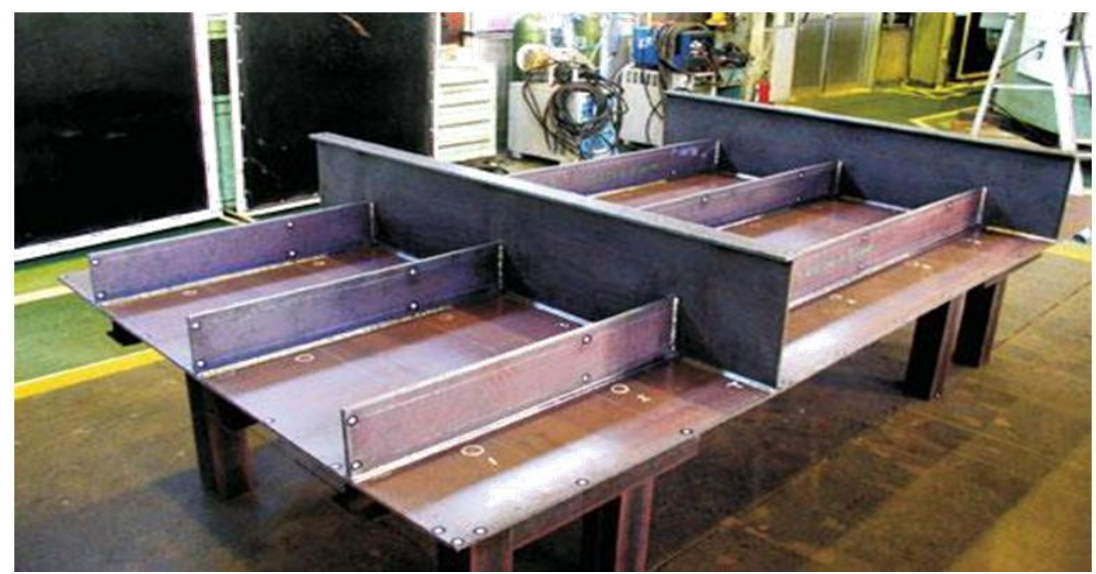

Fig.2.1 Figure of Experimental Mock up (Model I)



Fig.2.2. Figure of Asymmetrical curved block model (Model II)

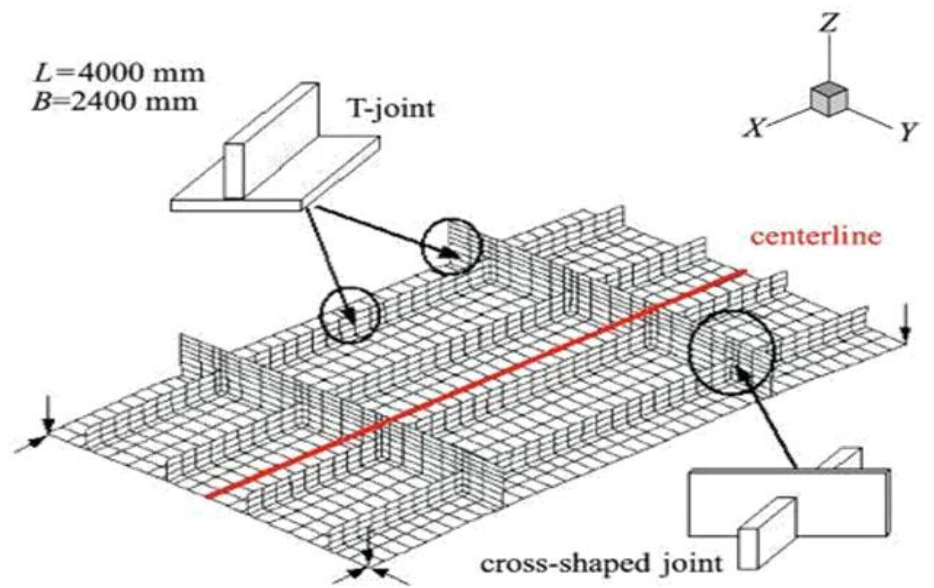

Fig.2.3. Figure of Thin plate structure (Model III)

Michleris and DeBiccari (2010) [7], presented a numerical analysis technique for predicting welding induced distortion. The technique combines two-dimensional welding simulation with three dimensional structure analyses in a decoupled approach. This technique is used for evaluating welding induced buckling, and this prediction can be utilizes either on design evaluation or manufacturing analysis tool.

They discuss methodology for predicting welding distortion and assessing the structural integrity of welded structures is presented. Thermo-elastic-plastic finite element analysis for welding simulation along with three dimensional elastic and eigen value finite element analysis are performed to predict both the applied weld load structure's critical buckling load. This approach is particularized on evaluating buckling under longitudinal stresses and implemented on panel structures for shipbuilding. This predictive approach can be implemented at 
various stages in the design and production cycle. In this the structure's critical buckling load is determine by single eigen value analysis.

This method can also be used to assess the effectiveness and establish the operating parameter for distortion mitigation techniques. Under some condition, it is not possible to establish condition where, the applied weld load can be kept lower than structure's critical buckling load because this require minimum weld size, or die to weight limitations, it is not possible to increase the plate thickness sufficiently to avoid buckling.

Deng et al. (2011) [8], they studied, welding distortion in a large thin-plate panel structure was predicted by means of elastic FEM based on inherent strain theory and interface element formation. The welding distortions in the plate model computed by large deformation theory and by small deformation theory were compared. Based on the simulation result he found that due to stiffness of a thin-plate welded structure is relative small, geometrical nonlinearity is apt to occur during assembly process. When the elastic FEM is used to predict welding deformation in a thin-plate structure, the large deformation theory should be involved in the elastic FEM. Simulation results suggested that welding procedure has a certain influence on the final welding distortion. Double-sided welding procedure can produce a large tendon force, so it can increase the buckling propensity especially in thin-plate structures. Assembly sequence has a significant effect on final distortion i.e. sequential welding will increase welding distortion. Elastic FEM can be also used to optimize welding procedure during the manufacturing stage.

Reddy B.N.S. and Swamy N.L.(2013) [9], had studied influence of groove angle in v-groove butt joints on transverse shrinkage in $\mathrm{co}_{2}$ arc welding process. Transverse shrinkages in welded structures results in reduced strength of welded joints. Experimental analysis of transverse shrinkage in single and double V-groove butt welded joints by varying groove angle and keeping heat input constant in $\mathrm{CO}_{2}$ Arc Welding process.

The transverse shrinkage increases with increase in the included angle in case of single V-groove butt joints for both $0.8 \mathrm{~mm}$ and $1.2 \mathrm{~mm}$ electrode wire diameter. Similar observation can be made on double Vgroove butt joints that, the transverse shrinkage increases with increase in the included angle for both $0.8 \mathrm{~mm}$ and $1.2 \mathrm{~mm}$ electrode wire diameter.

Chand R.R. et al. (2013) [10], had done numerical and experiment study of residual stress and strain in multipass GMA welding. Through 2D FE simulations of five pass GMA welding was performed on the $16 \mathrm{~mm}$ thick SS400 material, to determine residual stress, strain and deflection on the plate. The FE simulation results are verified by experimental results with similar weld conditions and geometry.

Based on the simulation results, the heat input and peak temperatures of weld pool are depend on the welding process parameter, voltage and current and travelling speed of welding touch, whereas temperature distribution, residual stress and deformation are dependent thermal material properties, heat input, the cooling rate and restrains on the plate. It is know that residual stress and strain distribution on top and bottom surface of the plate differs, due to heat distribution load applied to plate, the heat input and also the cooling time after each welding pass. The restraint of plate has also impact on residual stress and strain. The FEM results have much resemblance with the experimental residual stress pattern and magnitude.

Long H. et al. (2014) [11], they investigated distortions and residual stress induced in butt joint of thin plates using MIG welding. They concluded the following:-

- Thermo-elastic-plastic FE Methods combining with the double-ellipsoid heat flux model can be used to predict distortions and residual stresses of butt joint in thin plates during MIG welding provided the welding joint profile and the heat source parameters can be determined by correlating with experimental observations.

- Thermal analysis results show that the change of heat source parameters affects peak temperatures in the weld, and FZ and HAZ boundaries. Heat input to the welding pool is transferred quickly in the thickness direction of the plate and then in width and longitudinal directions to reach uniformed distributions. The heat conduction plays an important role in heat transfer, and the surface convection and radiation have little effect on FZ and HAZ boundaries. The increase of the welding speed causes temperature to decrease mainly in FZ but has a less effect to the areas outside FZ and HAZ.

- Higher Longitudinal shrinkages are observed in the weld than the outer rim of the plate.

- The largest transverse shrinkage occurs at the middle section of the length of the plate and it gradually reduces towards to the starting and ending edges of the welding line.

- Highest longitudinal tensile residual stresses are predicted in the weld area, which cause the material plastic deformation in the weld. Away from the weld area, the material of the parent plate experiences longitudinal compressive residual stresses but the magnitude of the stress is much smaller than the tensile stress in the weld. The transverse residual stress induced in the weld and plate is much smaller than the longitudinal residual stress. The highest transverse stress is in the weld and the majority of the plate is intension laterally along the length of the plate but the edges of the plate, where the welding starts and ends, are under compression. 
- When comparing with experimental results, FE simulation results predict the similar distribution trends of longitudinal and transverse shrinkages, and angular distortion. However, FE results may slightly underestimate the values of these distortions, especially for welding processes under lower welding speeds. Comparison of FE Simulation results with the existing empirical predictions shows that the empirical equations considerably underestimate the welding distortion in thin plates.

\section{Experimental work}

Though studies of distortion have been carried out by so many authors, still there is general lack of experimental data on different types of distortion such as transverse and longitudinal, shrinkage, angular distortion, bowing particularly for butt weld (v-groove) joint. However angular distortion has been studied but effect of different welding parameters on this type of distortion in butt weld cross-section is not fully clarified. Moreover availability of data on other types of distortion is so scare that verification of theoretical prediction is difficult. Hence it is necessary to perform some more experimental investigation on them.

So experimental were designed for measuring the following distortion of butt weld joints having different types of weld details and different thickness(e.g. $6 \mathrm{~mm}, 5 \mathrm{~mm} \& 4 \mathrm{~mm}$ ) of the plates.

1) Angular shrinkage

2) Longitudinal shrinkage

3) Transverse shrinkage

4) Bowing

The magnitude of above distortion were obtained by measuring the distance of the points which is punched on the plates, from three rectangular axis, $\mathrm{X}, \mathrm{Y}$ and $\mathrm{Z}$, before and after welding.

Before taking the measurements, the gap between the two plates to be joined by tacking the two plates with two small tacks at the two end of the plates. So that, their relative angular positions before joining will not create any problem while taking the measurement of transverse shrinkage as well as angular distortion respectively. Two plates to be joined are kept on a smooth plate. To avoid mismatch a spirit level was placed on these plates and then clamped by a fixture as shown in the figure 4.1

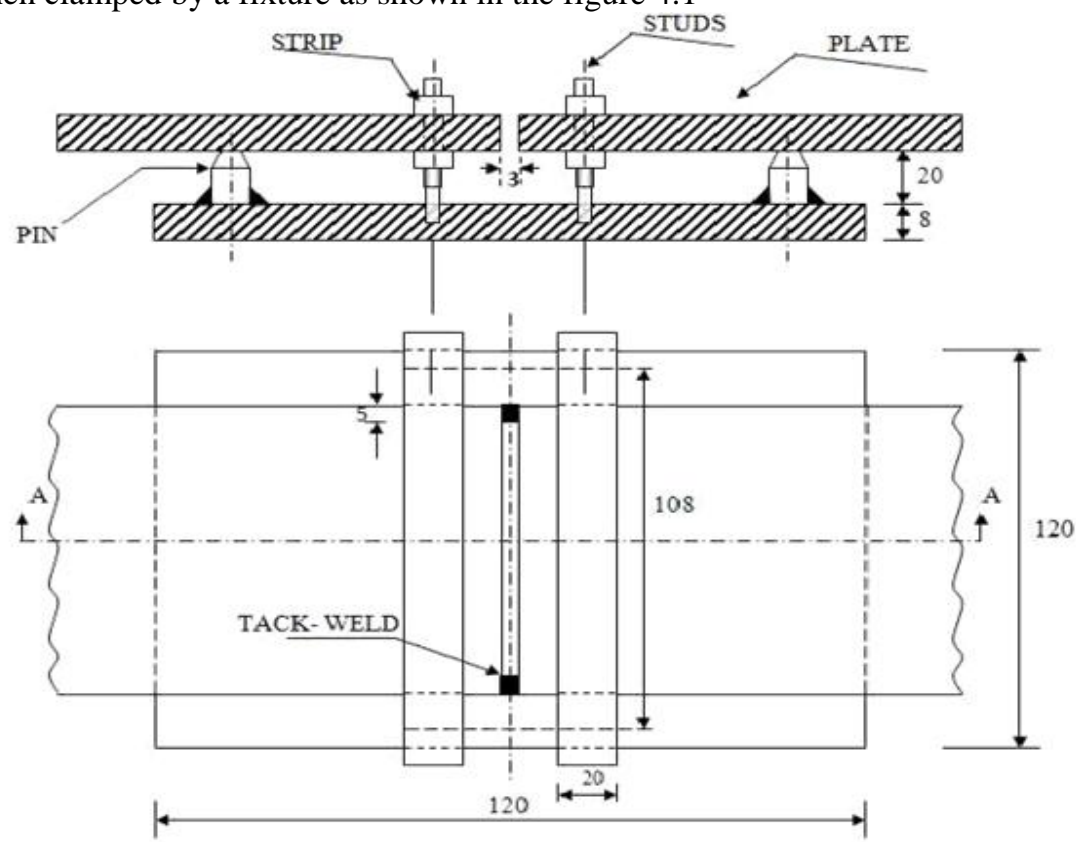

1. ALL DIAMENSIONS ARE IN mm.

2. NOT TO SCALE

\subsection{Test plate preparation}

Fig- 3.1: Figure of fixture used for holding the job

Thirty six numbers of $6 \mathrm{~mm}$ thickness test plates were cut by power hacksaw from a rolled Indian standard plate, ISP 16, having material specification mild steel (IS 226) and EN-31.

Tall has reported that low residual stresses developed due to power hacksaw cut, which was limited to a strip not wider than thrice plate thickness. Hence to eliminate the possibility of the effect of this residual stress on subsequent welding stress and distortion. The machining has been done with the help of shaper machine. Since it is wider than thrice the plate thickness, removed almost all the residual stresses leaving a negligible amount. All test plates of each side (i.e. thirty six numbers of plates) have been machined by the shaper machine after cut as pre required size and dimensions. Finally each plate of each side was machined in shaper machine to 
a size of $120 \mathrm{~mm}$ x $60 \mathrm{~mm}$ x $6 \mathrm{~mm}$ as per marking. Six plates of M.S. and EN-31 of thickness $6 \mathrm{~mm}$ is reduced to $5 \mathrm{~mm}$ through grinding. Similarly six plates of M.S. and EN-31 of thickness $6 \mathrm{~mm}$ is reduced to $4 \mathrm{~mm}$ through grinding. For each plate edge preparation was done on width side (Fig. 4.2) by shaping machine as per given dimension. Three types of edge preparation such as $120^{\circ}, 90^{\circ} \& 60^{\circ}$ single vee were made on the test plates. Each of these pairs of plates having same edge preparation were aligned and clamped in a fixture. The plates were then tack welded from both end up to the length of $3 \mathrm{~mm}$.as shown in Fig 4.1. Each of these 18 numbers of pairs of plates was numbered as a job for easy understanding and working.

The jobs were numbered from-

W1, W2, W3, W4, W5, W6, W7, W8, W9, W10, W11, W12, W13, W14, W15, W16, W17 \& W18

This indicates three type of weld design. To mark 30 numbers of points on reverse side of the plate, each job was colour with chalk see fig.4.3. Use knife edge of a height gauge for drawing horizontal and vertical lines on the jobs for getting the intersecting lines as per dimensions as shown in the fig.4.3. The intersecting lines thus generate 30 gauges points on the surfaces of the job. These points are then punched with high pressure so that the holes so formed can be seen while taking the measurement.

The horizontal lines are marked on the job as AA, BB, CC, DD and EE from the top and the vertical lines are marked as 1-1,2-2,3-3,4-4,5-5,6-6,7-7 and 8-8 from left to right of the job as shown in fig.4.3.

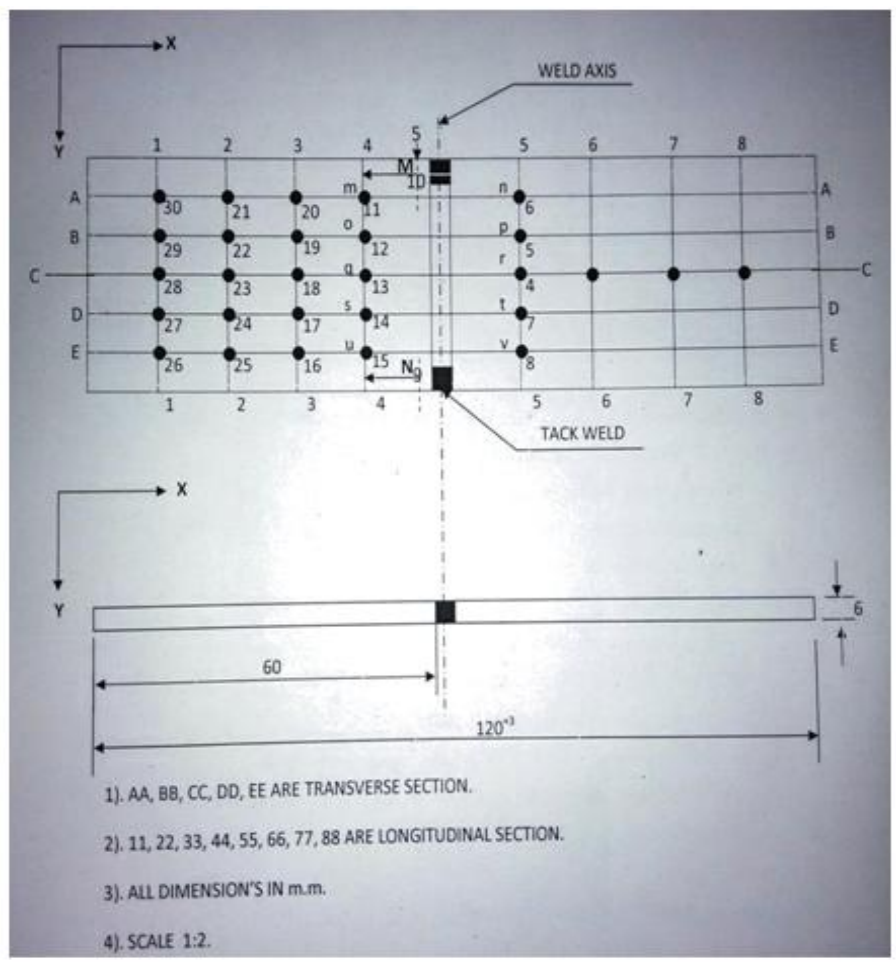

Fig. 4.3 Figure of Layout of gauge points

The nomenclature of the 30 numbers gauge points has been listed below in tabular form.

The above 30 numbers of gauge points are used to find the angular distortion and bowing. Only 10 numbers of gauge points of the above are used to find out the transverse shrinkage. These points are again renamed by the letters. Please refer Fig4.3. These points are lying on either side of central Y-axis at equal distances. As including the central Y-axis the vertical lines are equal spaced. For measurement of longitudinal shrinkage two more points $\mathrm{M}$ and $\mathrm{N}$ are marked near the weld zone.

\subsection{Apparatus used}

To measure the several types of distortions discussed earlier following apparatus and accessories were used.

- Dial indicator with universal stand. (least count $0.001 \mathrm{~mm}$.)

- Vernier calliper. (least count $0.02 \mathrm{~mm}$.)

- Lens (focus $100 \mathrm{~mm}$.)

- Punch (made by carbon steel material)

- Try square (least count $1 \mathrm{~mm}$.)

- Spirit level (made by cast iron) 
- Knife-edge (made by carbon steel material)

- $\quad$ Steel-scale (least count $0.5 \mathrm{~mm}$.)

- Height-gauge (made by stainless steel material)

- Ground angle plate (made by cast iron)

4.3 Machine used

For preparation the work piece following machines are used.

1. Power Hacksaw: Model No.-HS 30

Specifications:-

- $\quad$ Stock length for blade $325 * 38 * 2 \mathrm{~mm}$. made by high speed steel.

- 3 phase power supply

- Heavy duty machine

- Cutting pressure- 1 to $10 \mathrm{~kg} / \mathrm{cm}^{2}$

2. Shaper Machine: Modal No. CSM-63

Specifications:-

- Max. Length of stroke - $630 \mathrm{~mm}$.

- Max. Horizontal travel of table $-650 \mathrm{~mm}$.

- Max. Travel of table $-370 \mathrm{~mm}$.

- Minimum travel of tool $-105 \mathrm{~mm}$.

- Floor space $-2200 * 127 \mathrm{~mm}$.

- Driving motor power $-2.2 \mathrm{KW}$.

- Weight $-1480 \mathrm{Kg}$.

3. Surface Grinder Machine:

Specifications:-

- Non hydraulic

- Non automatic

- Fully manually operated horizontal surface grinder

- Max. Travel slide $-450 \mathrm{~mm}$.

- Minimum cutting capacity - 1 thou

- Material of wheel - aluminium oxide

- Dia. $200 * 13 * 31.75 \mathrm{~mm}$

- Grit specification - 38A 46/54 K5VBE

4. Bench Grinder Machine:

Specifications:-

- Double ended bench grinder with two wheels

- Wheel used - carburandam wheel (1 fine,1 coarse)

- Size $-250 * 25 \mathrm{~mm}$.

\subsubsection{Angular distortion}

Measurement of angular distortion can be taken with the help of dial gauge indicator with universal stand (Fig.4.4.1.1). A job was placed on the surface of the table before welding. The height of each point was measured along $\mathrm{Z}$-axis from datum line.

The dial gauge reading was noted down and shown in a tabular fashion. In this way 30 numbers of gauge points reading has been taken by using the dial gauge indicator with universal stand.

Similar procedure has been followed for taking the reading after welding by dial gauge. The same job was placed on the surface table after butt welding. The height of the above 30 numbers of gauge point were measured by dial gauge indicator with universal stand from the same reference line or datum line. Hence the amount of distortion along Z-axis can be found out by taking the difference of reading of the heights of point from the same datum line. While taking the reading of heights of each with the help of dial gauge before and after welding of the same job, three set of reading have been taken and the average height was found out to reduce error keeping the datum line fixed or same for all measurements. In this way the average distorted height along any longitudinal section was calculated. For longitudinal sections (see Fig-4.3) the average distorted height of all 10 number of gauge points has been taken which is covering almost the entire length of the job, was found out and then plotted on graph paper. The nature of graph shows the job has been distorted in an angular fashion. Hence this type of distortion is known as angular distortion. 
Similar process has been carried out for all the jobs (i.e. $\mathrm{W}_{1}$ to $\mathrm{W}_{18}$ ) for calculating angular distortion and then plotted on graph papers which is shown in the table 5.1 to table 5.4.

From the graph the angular distortion or the distorted angle of each job was calculated which is shown in next chapter.

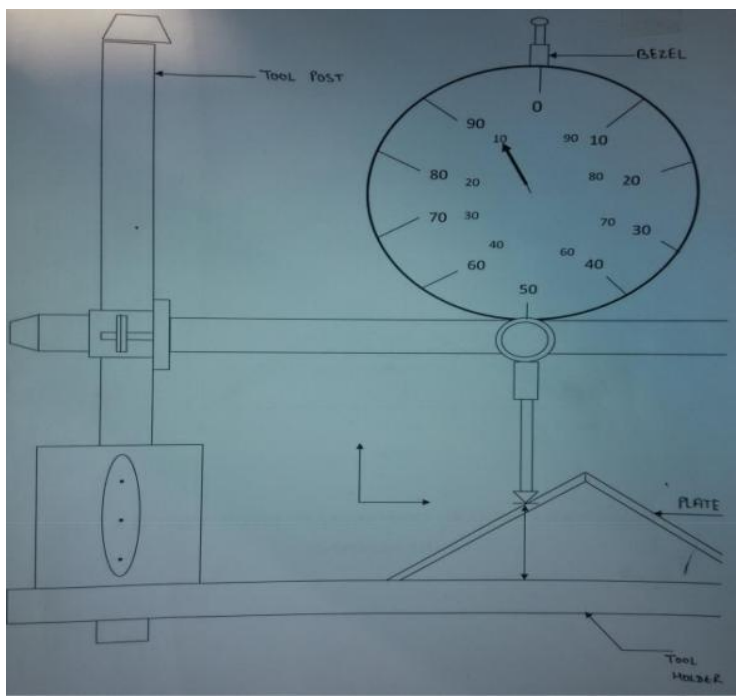

Fig. 4.4.1.1 Figure of Universal dial gauge

\subsubsection{Transverse shrinkage}

For the measurement of transverse shrinkage of distance between the points lying on either side of weld axis a vernier scale was used. The vernier constant is $0.02 \mathrm{~mm}$. i.e. the accuracy is of the order of 20 micron. In Fig.4.3 the distances between the points $\mathrm{mn}$, op, qr, st and uv, were found out before and after welding to get the transverse shrinkage of all the jobs Table No.5.5 (in chapter -V) shows the amount of transverse shrinkage of all the jobs from $\mathrm{W}_{1}$ to $\mathrm{W}_{18}$.

Transverse shrinkage was only noticed on the points lying perpendicular and closes to the axis of the weld. The distances were measured along $\mathrm{X}$-axis before and after welding. The sketch of transverse shrinkage is shown in Fig.1.1.

\subsubsection{Longitudinal shrinkage}

The longitudinal shrinkage was measuring by using a vernier scale having vernier constant $0.02 \mathrm{~mm}$. The distance between the points $\mathrm{M} \& \mathrm{~N}$ (or between the points 9 to 10) shown in fig 4.3. were measured to calculate the longitudinal shrinkage. The points $\mathrm{M}$ and $\mathrm{N}$ are very nearer to the axis of the weld.

\subsubsection{Accuracy}

On the smooth surface of the job a very fine holes were punched to located the gauge points for the distortion measurement. It is very difficult to bring the tip points of measuring instrument exactly on the centre of the gauge points. To overcome this difficulties three sets of reading were taken at a point and then average of those three reading were considered for deflection or distortion value. This technique was chosen to eliminate the error and hence thinking of placing the instrument exactly the centre of gauge points. An initial pressure was given to the dial gauge indicator to increase the sufficiency of measuring procedure and hence enables the slightest deflection of the dial gauge indicator. The accuracy of dial gauge was $0.01 \mathrm{~mm}$. i.e.

of the order of 10 microns. Other than dial gauge a vernier scale is also used to measure the distances of the gauge points within the accuracy of 20 microns.

\subsubsection{Welding condition}

Welder's efficiency : More than $80 \%$

Position : Flat (Horizontal)

Welding speed $\quad: 0.06 \mathrm{~m} / \mathrm{min}$ (normal speed)

Current : 80-100 amps (AC)

Voltage : 100 volts

Electrode size $: 3.15 \mathrm{~mm}$.

Process applied : Manual metal arc welding.

Detail of Electrode-(SWG 10) 
SWG - Standard wire gauge

Size- $\quad 3.15 \mathrm{~mm} .(\varphi) \times 450 \mathrm{~mm} .(\mathrm{L})$

(Flux coated for mild steel)

Coading- IS: 814-1991 ER 4111

AWS: A51 1983 E6013

(Made by TIRUPATI ELECTRODES (P) LTD. HOWRAH)

Current- 60-125 Amp.

Voltage- $\quad 80$ Volts

\subsubsection{Photographs}

There are nine photographs in 4.4.6.1 of EN-31 Plate of dimension $120 \mathrm{mmX} 60 \mathrm{mmX} 6 \mathrm{~mm}$. The thickness of the plates has to be made as mentioned in the photographs. Vee grooves are also to cut on these plates as mentioned in the photographs. These pictures are taken after cutting the plates from the length of bar.


Fig. 4.4.6.1 Figure of EN-31 plate of dimension 120mmX60mmX6mm

There are nine photographs in 4.4.6.2 of Mild Steel Plate of dimension 120mmX60mmX6mm. The thickness of the plates has to be made as mentioned in the photographs. Vee grooves are also to cut on these plates as mentioned in the photographs. 
Experimental Study of Distortion in Butt Welds of Mild Steel Plates and En-31 Plates Having



\section{MS PLATE \\ Thickness - GMm \\ $120 \mathrm{~mm} \times 60 \mathrm{~mm}$}
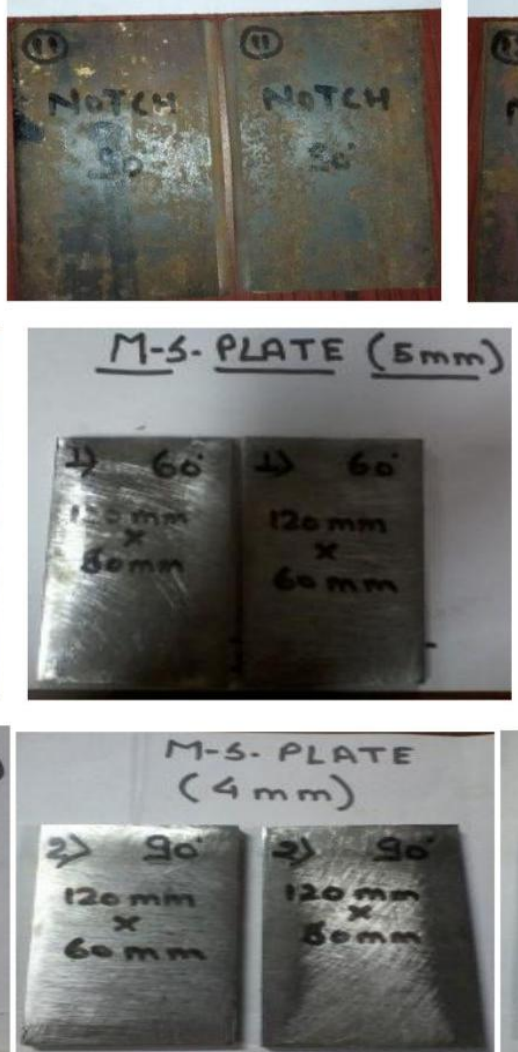

MS PLATE

Thickness - GMM

$120 \mathrm{~mm} \times 60 \mathrm{~mm}$
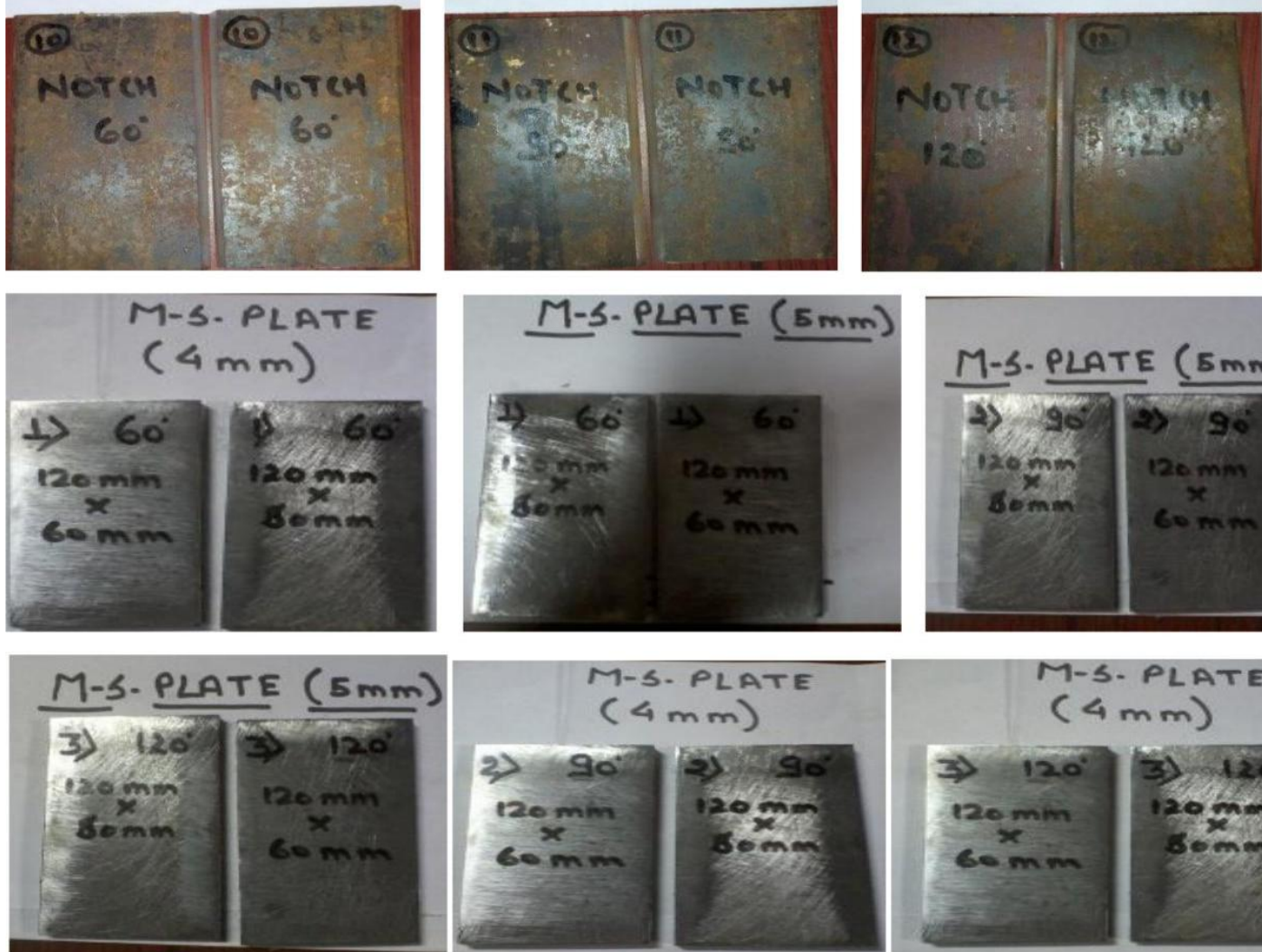

Fig. 4.4.6.2 Figure of M.S. plate of dimension 120mmX60mmX6mm

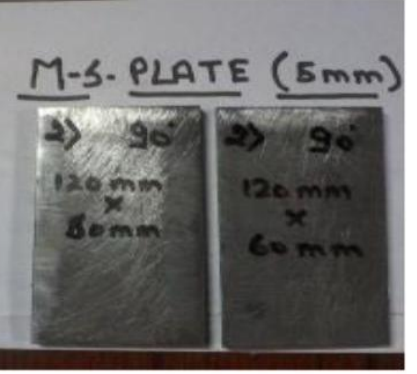

Photographs from 4.4.6.3 to 4.4.6.6 of EN-31 Plate and Mild Steel Plates are taken after grinding process had been done to reduce the respective thickness.

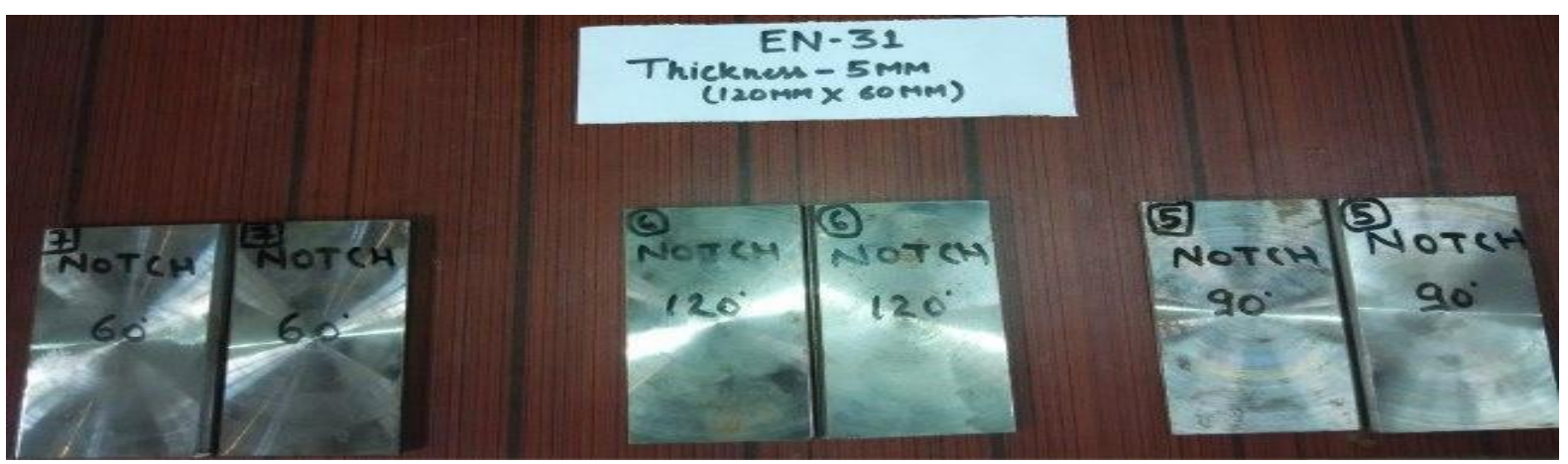

Fig. 4.4.6.3 Figure of EN-31 plate of dimension 120mmX60mmX5mm

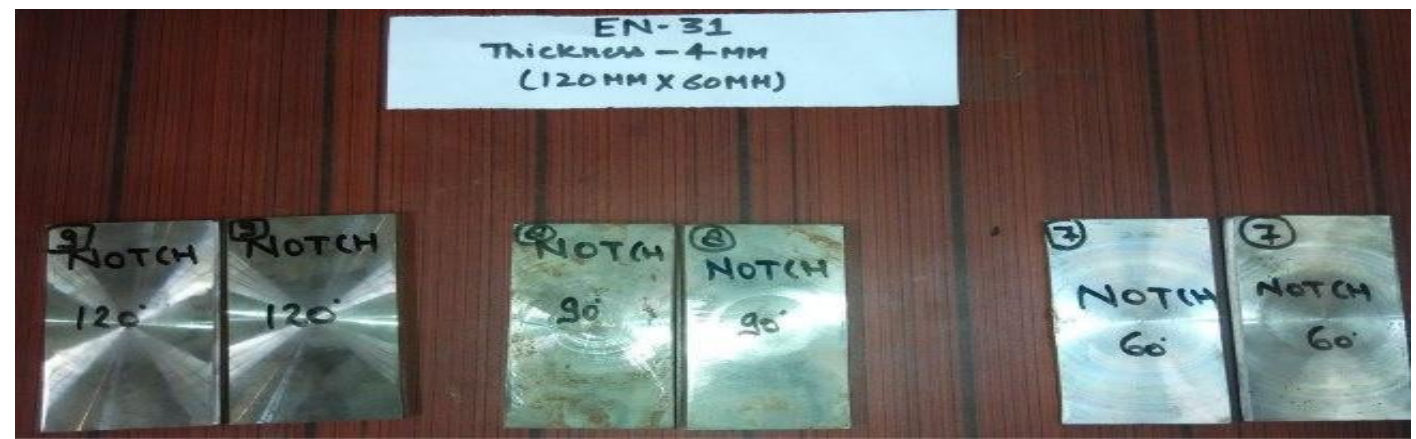

Fig. 4.4.6.4 Figure of EN-31 plate of dimension 120mmX60mmX4mm 


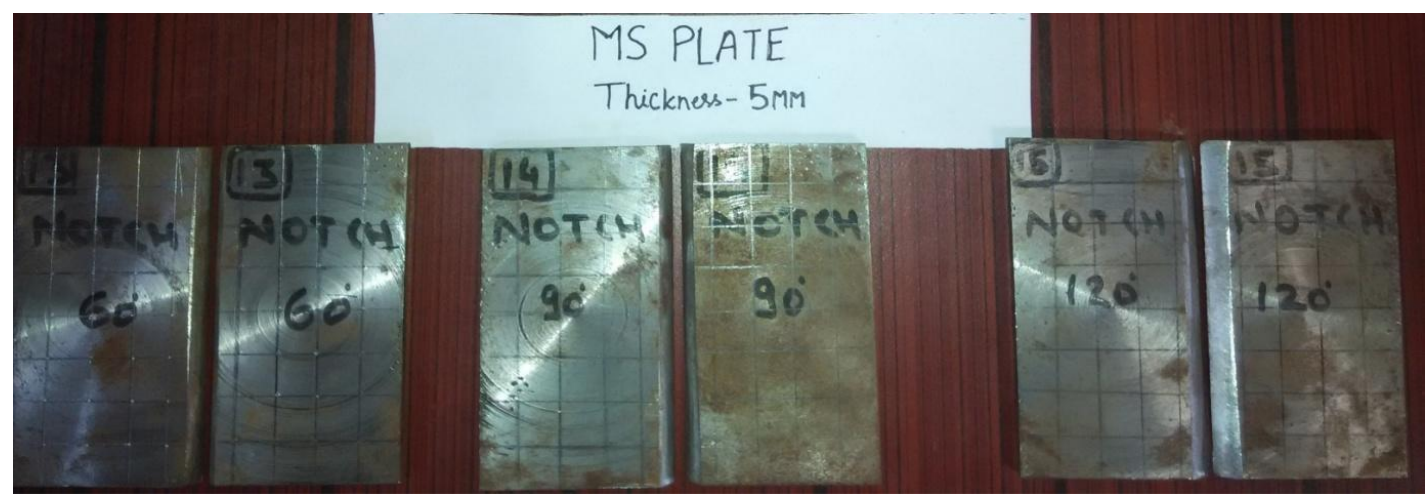

Fig. 4.4.6.5 Figure of M.S. plate of dimension 120mmX60mmX5mm

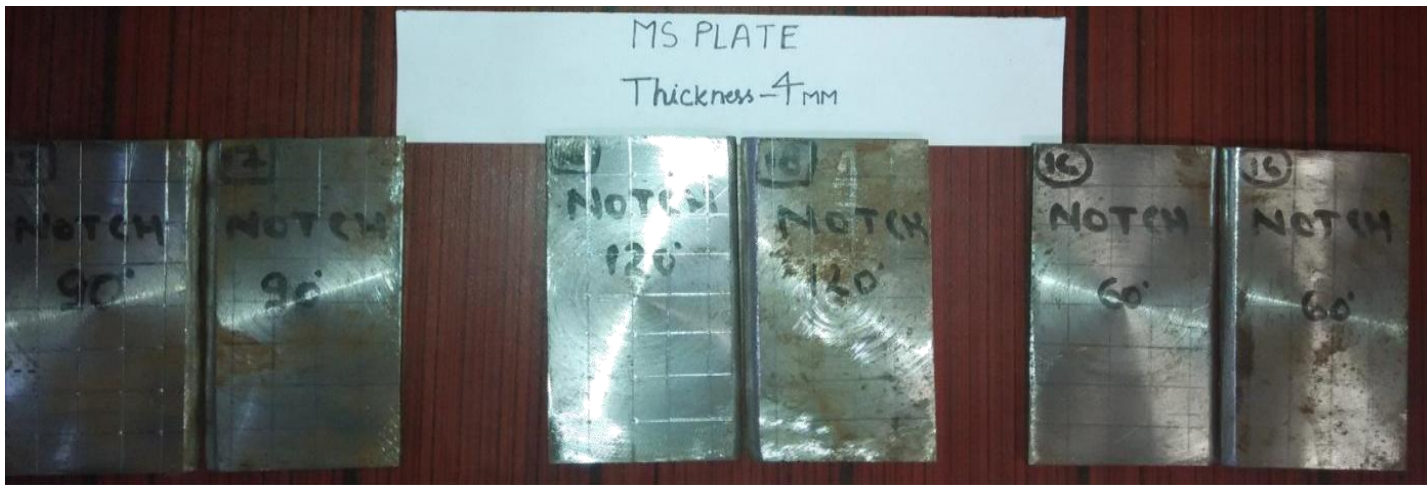

Fig. 4.4.6.6 Figure of M.S. plate of dimension 120mmX60mmX4mm

Photographs from 4.4.6.7 to 4.4.6.12 of EN-31 Plate and Mild Steel Plates are taken after making notches, marking, punching and tack welding of the plates.

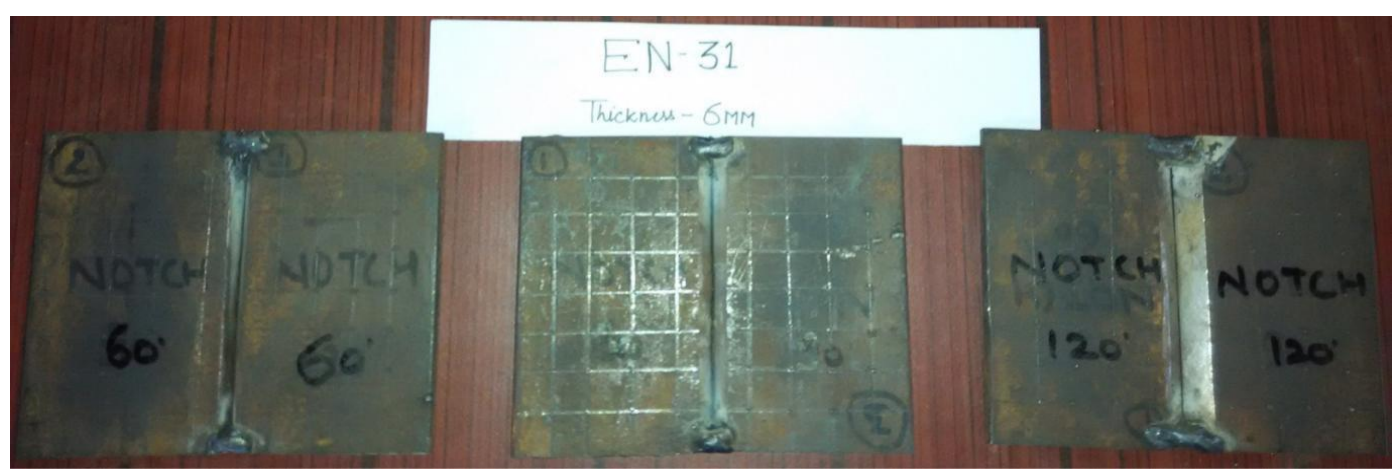

Fig. 4.4.6.7 Figure of EN-31 plate of dimension 120mmX60mmX6mm

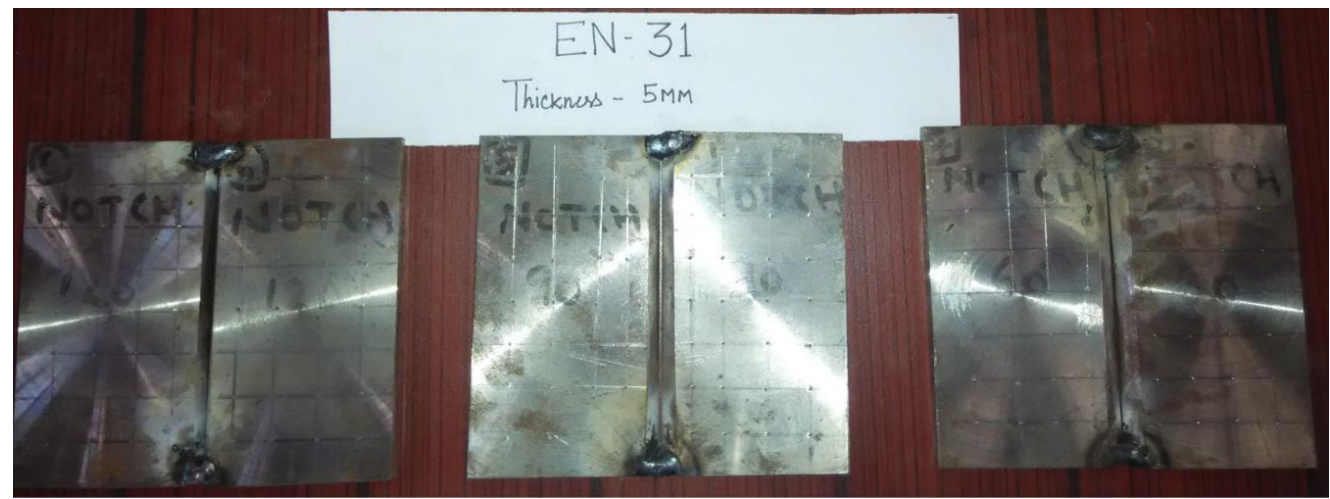

Fig. 4.4.6.8 Figure of EN-31 plate of dimension 120mmX60mmX5mm 


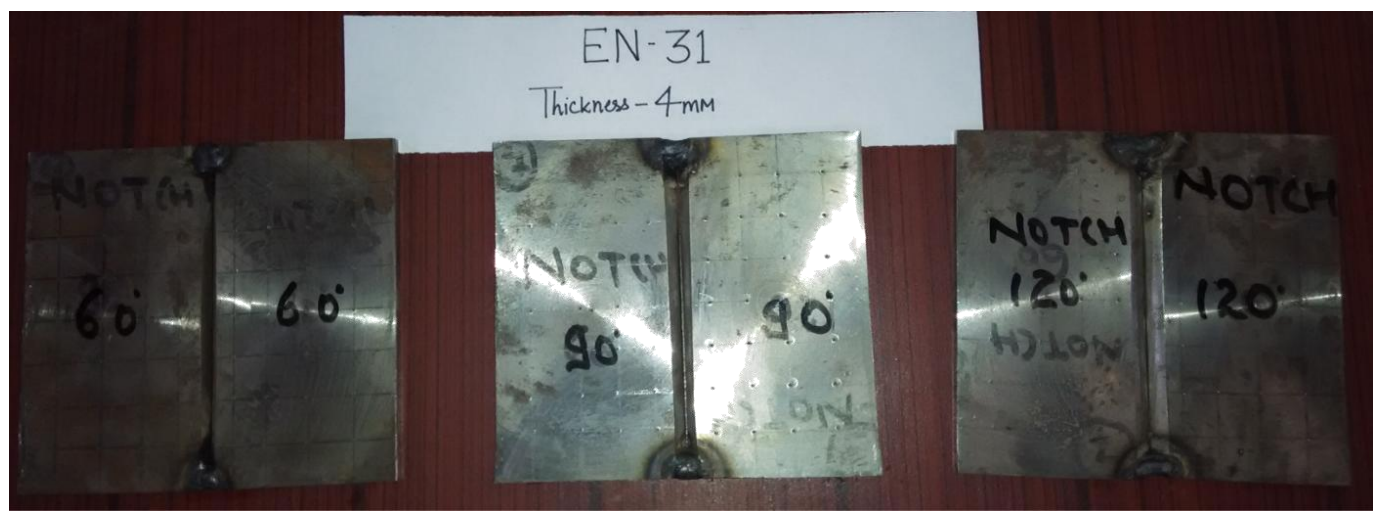

Fig. 4.4.6.9 Figure of EN-31 plate of dimension 120mmX60mmX4mm



Fig. 4.4.6.10 Figure of M.S. plate of dimension 120mmX60mmX6mm

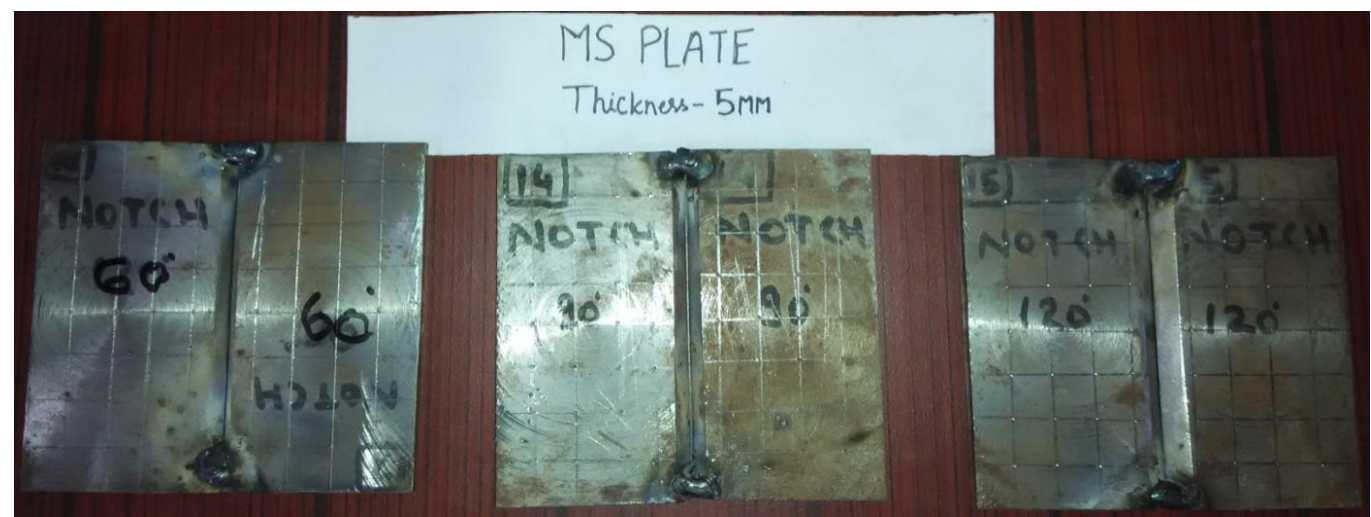

Fig. 4.4.6.11 Figure of M.S. plate of dimension $120 \mathrm{mmX} 60 \mathrm{mmX} 5 \mathrm{~mm}$

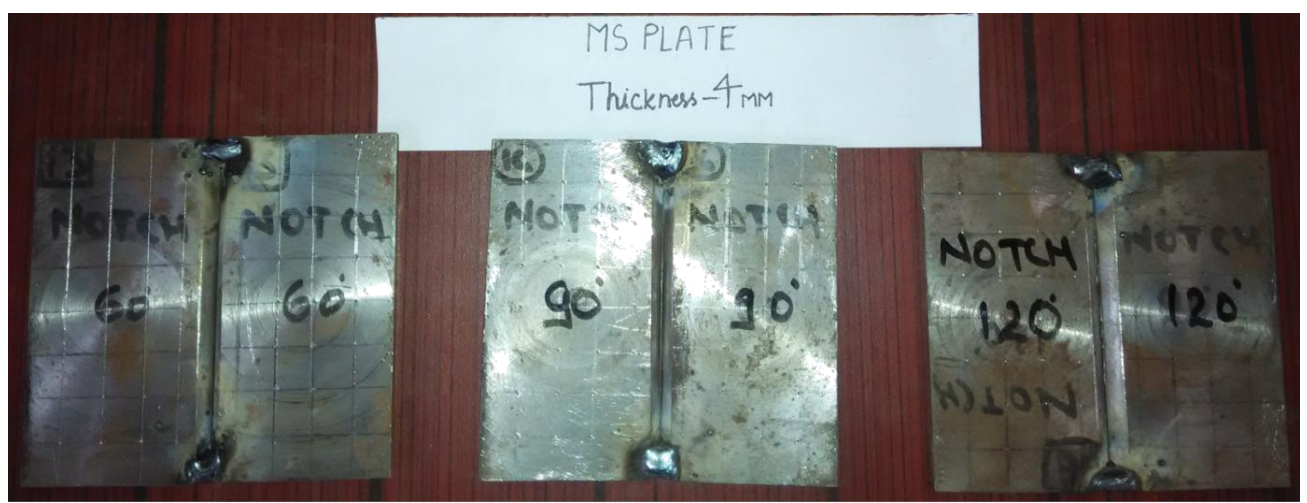

Fig. 4.4.6.12 Figure of M.S. plate of dimension 120mmX60mmX4mm 
Photographs from 4.4.6.13 to 4.4.6.19 of EN-31 Plate and Mild Steel Plates after complete welding of the plates had been done.

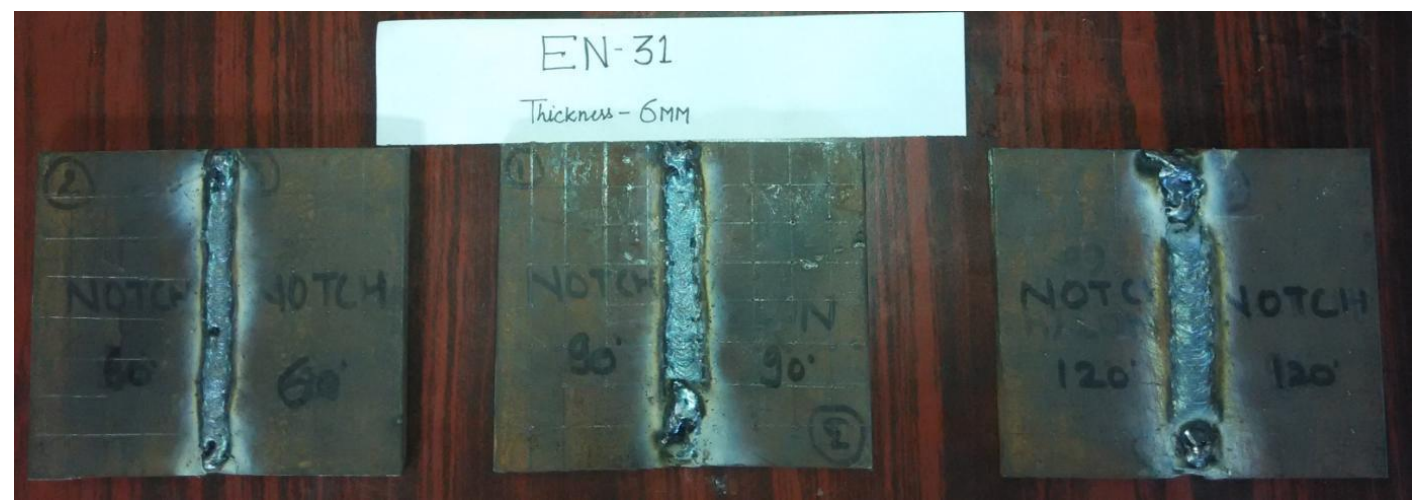

Fig. 4.4.6.13 Figure of EN-31 plate of dimension 120mmX60mmX6mm

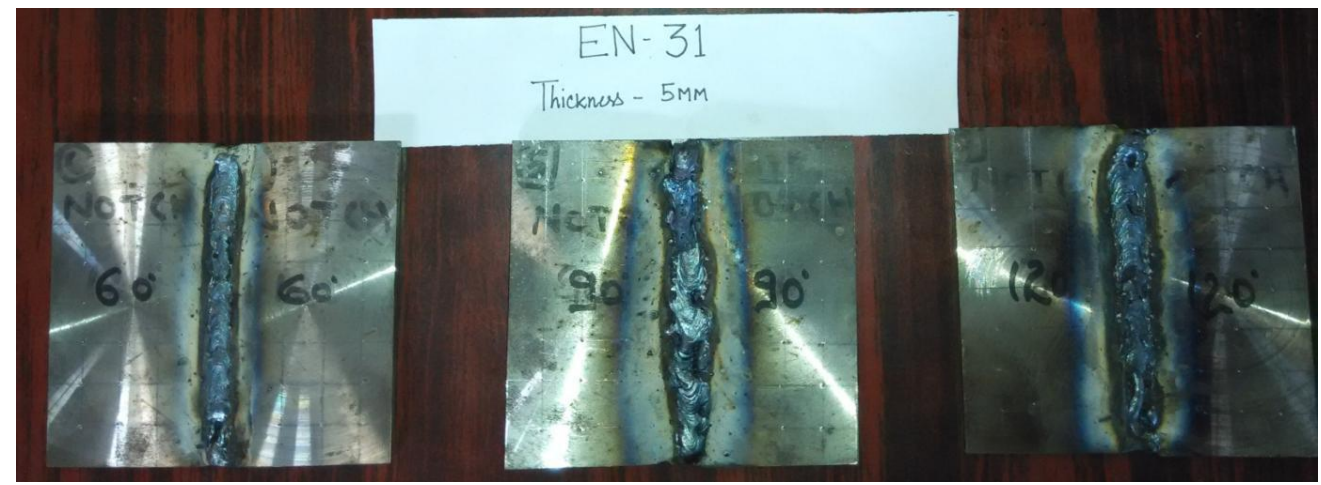

Fig. 4.4.6.14 Figure of EN-31 plate of dimension 120mmX60mmX5mm

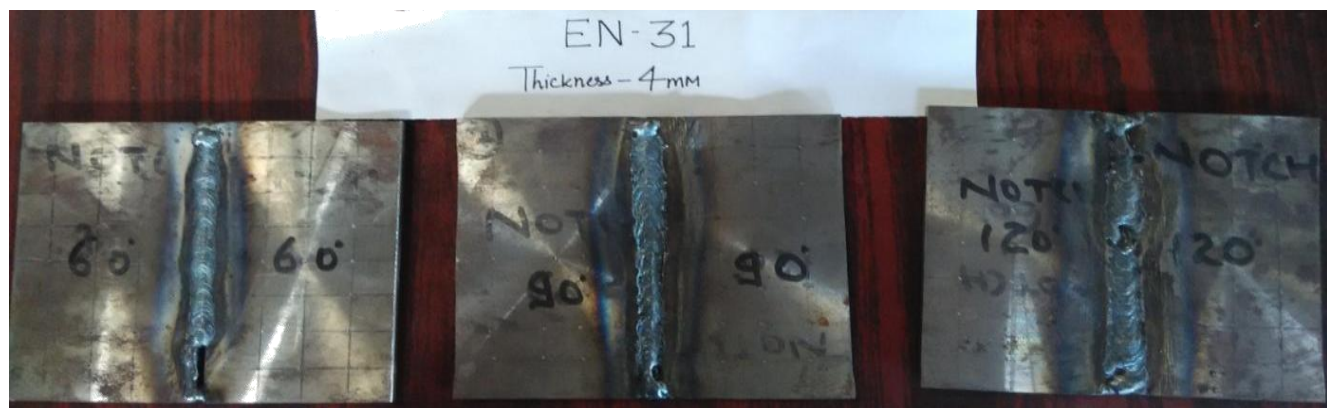

Fig. 4.4.6.15 Figure of EN-31 plate of dimension 120mmX60mmX4mm

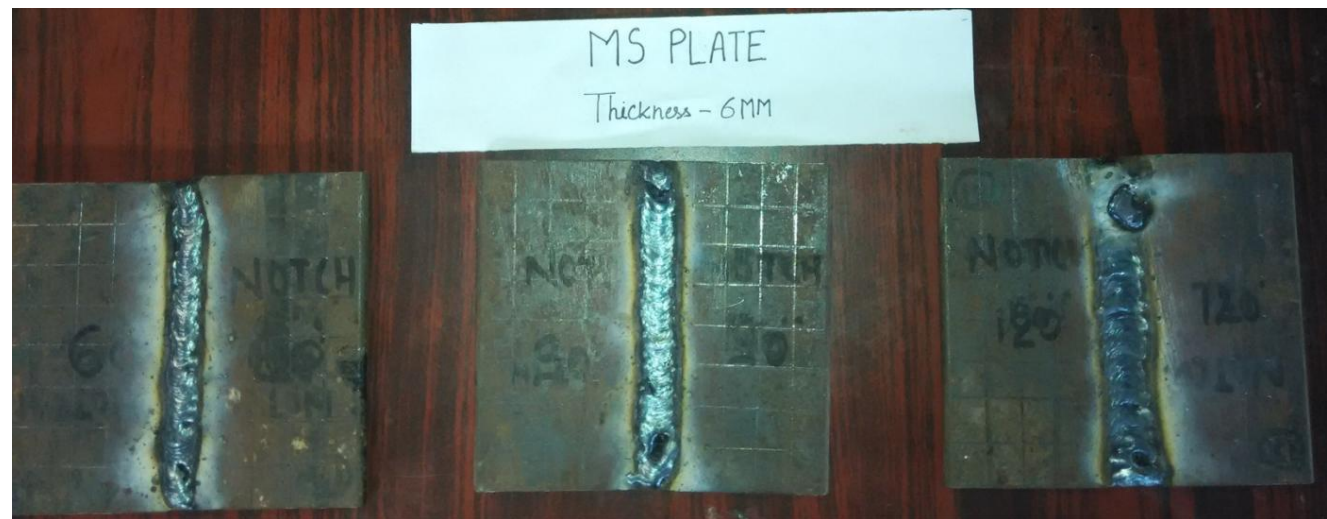

Fig. 4.4.6.16 Figure of M.S. plate of dimension 120mmX60mmX6mm 


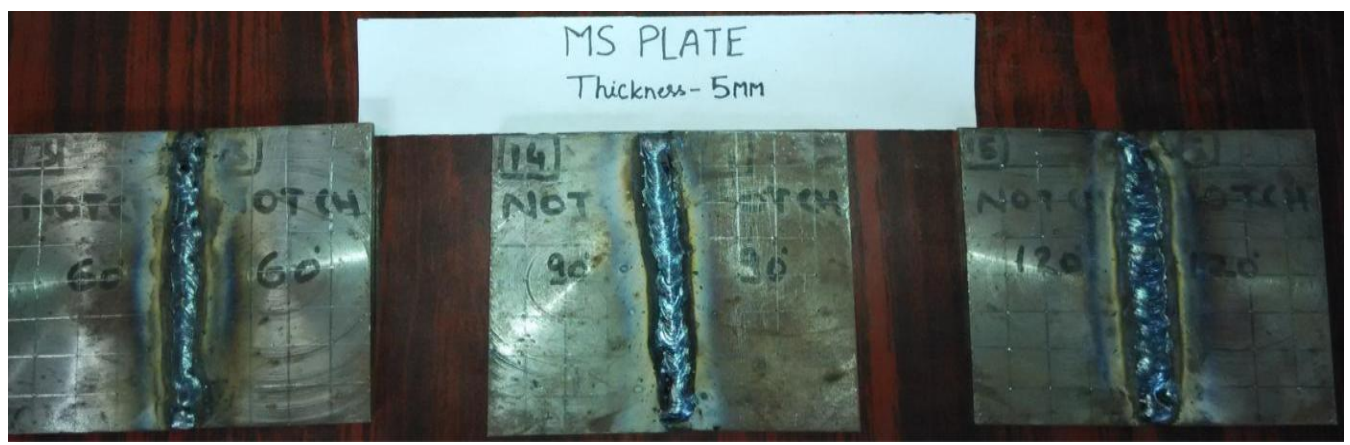

Fig. 4.4.6.17 Figure of M.S. plate of dimension 120mmX60mmX5mm

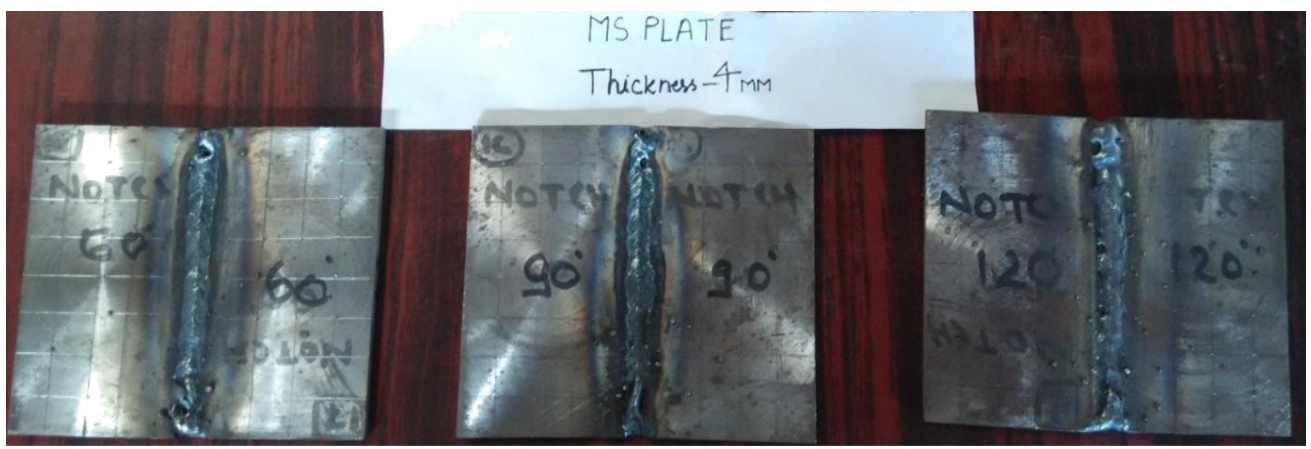

Fig. 4.4.6.18 Figure of M.S. plate of dimension 120mmX60mmX4mm

\section{Results And Discussions}

To The motive of the thesis work is to study the distortion due to butt welding on low carbon structural steel (mild steel) and medium carbon steel (EN-31) having different plate thickness and different V-groove angles. The material specification is IS 226. The weld cross-section detailed of $120^{\circ}$ vee, $90^{\circ}$ vee, and $60^{\circ}$ vee has been taken from IS 823-1964. The experimental results are shown in different tables 5.1 to 5.6.

\subsection{Angular distortion}

For Angular distortion measurement the table No. 5.1 to 5.4 are to be considered. The average distorted height along Z-axis is taken for each and every point lying along longitudinal section 1-1, 2-2, 3-3, 4-4, 5-5, 6-6, 7-7 and 8-8. The average distorted height of a point is found out by taking difference between after welding and before welding reading measured by means of a universal dial gauge. Three sets of reading were taken for each case to get better result. In this way the average distorted height were found out along a transverse section. A schematic arrangement is given in Fig.4.4.1.1. Here to show how a dial gauge indicator was used to get the deflection of a point lying on a distorted butt-welded joint plates.

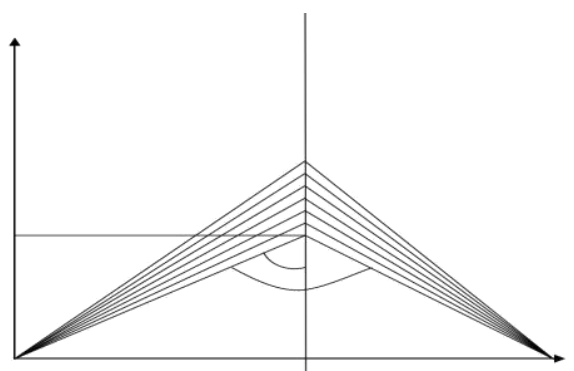

Fig 5.1 Figure of Sketch for measurement of angular distortion (y-deflection)

\section{For example}

Consider a table 5.1 along section 1-1, there are five points numbered 26 to 30 (which is in Fig 4.4). The average distorted height of the above is $2.9 \mathrm{~mm}$. The above five points are 30,29,28,27 and 26 corresponding to point $A_{1}, B_{1}, C_{1}, D_{1}$ and $E_{1}$ respectively . At point $A_{1}$ the reading is shown $2.9 \mathrm{~mm}$. This is the distorted height of the point obtained by measuring the difference in height after welding and before welding.

At point $A_{1}$ three sets of reading were taken before and after welding. Then there average value was found to get good result and in this case it is $2.54 \mathrm{~mm}$. The average of the above five points is $2.9 \mathrm{~mm}$. This is shown at bottom of the table along the column average.

\begin{tabular}{lll}
\hline DOI: $10.9790 / 1684-1403045180$ & www.iosrjournals.org & $68 \mid$ Page
\end{tabular}


From Table 5.4 it is obtained that the average angular distortion for the jobs along transverse axis $2.8211 \mathrm{~mm}$. ,2.1757 mm. ,1.8516 mm. , $3.0489 \mathrm{~mm}$. , $1.6883 \mathrm{~mm} .1 .405 \mathrm{~mm}$. , $2.2889 \mathrm{~mm}$., $1.9727 \mathrm{~mm}$., 1.7817 mm. , 3.4989 mm. , 2.6469 mm, 1.8395 mm. , 1.7897 mm. , $1.6661 \mathrm{~mm}$. , 1.5675 mm. , $2.2131 \mathrm{~mm}$. , $1.8964 \mathrm{~mm}$. and $1.4281 \mathrm{~mm}$. These average values are plotted on a graph to get angular distortion of the jobs which is shown graph 5.1 to graph 5.6.

$\mathrm{X}$-axis is the direction along the thickness of the job.

$\mathrm{Y}$-axis is the direction along the distortion (shrinkage) of the job.

From the graph it has been found that the angular distortion is different in different values of the job taking weld axis as central line.

From the sketch-I average angular distortion is $2 \theta^{0}$ and corresponding deflection is $\mathrm{Y}$ mm. i.e. $1^{0} 58^{\prime}$ 53 " and $2.8211 \mathrm{~mm}$. respectively. And here the angular deflection

$(2 \theta)$ is taken and it changes by the converter i.e. in "degree, minutes and seconds".

Let, us taken three type of $6 \mathrm{~mm}$. thick plate of mild steel and EN-31 having different edge preparation of $120^{\circ}, 90^{\circ} \& 60^{\circ}$ Vee for further discussion. The six jobs are designated by $\mathrm{W}_{1}, \mathrm{~W} 2, \mathrm{~W}_{3}, \mathrm{~W}_{10}, \mathrm{~W}_{11}$ \& $\mathrm{W}_{12}$ and the corresponding angles are $60^{\circ}, 90^{\circ}, \& 120^{\circ}$ respectively. In the above mentioned process the angular distortion and the average angular distortion graphs are drawn by taken the values of distortion from the Table 5.1, $5.2 \& 5.3$. These graphs are shown in graph 5.1 to graph 5.6. The average angular distortion of the jobs $\mathrm{W}_{1}$ $, \mathrm{W}_{2}, \mathrm{~W}_{3}, \mathrm{~W}_{10}, \mathrm{~W}_{11}$, and $\mathrm{W}_{12}$ are given in Table No.5.1

Table - 5.1 Table of Average angular distortion in plates of thickness $6 \mathrm{~mm}$

\begin{tabular}{|c|c|c|c|c|c|}
\hline Job & Plate & Weld & Average & Deflection & Material \\
\hline No. & thickess & section & angular & in $\mathrm{Y} \mathrm{mm}$. & (Mild steel \\
\hline & in $\mathbf{~ m m}$. & in & distortion & & or EN-31) \\
\hline & & degree & $2 \theta^{0}$ & & \\
\hline & & & {$\left[\theta^{0}=\left(\theta_{1}{ }^{0}+\theta_{2}{ }^{0}\right) / 2\right]$} & & \\
\hline & & & & & \\
\hline$W_{1}$ & 6 & $60^{\circ}$ & $1^{0} 58^{\prime} 53^{\prime \prime}$ & 2.8211 & EN-31 \\
\hline $\mathrm{W}_{2}$ & 6 & $90^{\circ}$ & $1^{0} 5238^{\prime \prime}$ & 2.2889 & EN-31 \\
\hline $\mathbf{W}_{3}$ & 6 & $120^{\circ}$ & $1^{0} 14^{\prime} 23^{\prime \prime}$ & 1.7897 & EN-31 \\
\hline W10 & 6 & $60^{\circ}$ & $3^{0} 07^{\prime} 39^{\prime \prime}$ & 3.0489 & M.S. \\
\hline W11 & 6 & $90^{\circ}$ & $3^{0} 04^{\prime} 52$ & 3.4989 & M.S. \\
\hline W12 & 6 & $120^{\circ}$ & $2^{0} 52^{\prime} 13^{\prime \prime}$ & 2.2130 & M.S. \\
\hline
\end{tabular}

Here, it can be compared that for same plate thickness the angular distortion or the average distortion is lower for greater weld cross-section.

\section{Example}

The weld cross-section of $\mathrm{W}_{3}$ is greater than $\mathrm{W}_{1}$ is also greater than $\mathrm{W}_{2}$, hence angular distortion of $\mathrm{W}_{3}$ is lower than $\mathrm{W}_{1}$ and $\mathrm{W}_{2}$. In other word it can be said that for same plate thickness the angular distortion increases. If the heat input increases due to greater weld metal deposition. The average angular distortion of 6 $\mathrm{mm}$. plate lies between $1^{0} 14{ }^{\prime} 23^{\prime \prime}$ from $1^{0} 58^{\prime} 53^{\prime \prime}$ (for EN-31 plate) and $2^{0} 52$ ' 13 " to $3^{0} 07^{\prime} 39^{\prime \prime}$ (for mild steel) above specified weld cross-section. The distortion is minimum or zero at fourteen points or both the end of the jobs. The angular distortion and the average angular distortion of another type of jobs having plate thickness 4 $\mathrm{mm}$. for different weld cross-section $60^{\circ}, 90^{\circ}$ and $120^{\circ}$ are given in the Table 5.2 by the following the similar method discussed as above.

Table - 5.2 Table of Average angular distortion in plates of thickness $4 \mathrm{~mm}$

\begin{tabular}{|c|c|c|c|c|c|}
\hline Job & Plate & Weld & Average & Deflection & Material \\
\hline \multirow[t]{5}{*}{ No. } & thickness & section & angular & in Y mm. & (Mild \\
\hline & in $\mathbf{m m}$. & in & distortion & & steel or \\
\hline & & degree & $\left(2 \theta^{0}\right)$ & & EN-31) \\
\hline & & & {$\left[\theta^{0}=\left(\theta_{1}{ }^{0}+\theta_{2}{ }^{0}\right)\right.$} & & \\
\hline & & & /2] & & \\
\hline $\mathbf{W}_{7}$ & 4 & $60^{\circ}$ & $0^{\circ} 59^{\prime} 53^{\prime \prime}$ & 1.8516 & EN-31 \\
\hline $\mathbf{W}_{8}$ & 4 & $90^{0}$ & $1^{0} 02^{\prime} 29^{\prime \prime}$ & 1.7817 & EN-31 \\
\hline $\mathrm{W}_{9}$ & 4 & $120^{\circ}$ & $1^{0} 07^{\prime} 13$ & 1.5675 & EN-31 \\
\hline W16 & 4 & $60^{\circ}$ & $1^{0} 54^{\prime} 52$ & 1.4050 & M.S. \\
\hline W17 & 4 & $90^{\circ}$ & $1^{0} 29^{\prime} 56^{\prime}$ & 1.8395 & M.S. \\
\hline W18 & 4 & $120^{0}$ & $1^{0} 58^{\prime} 53^{\prime \prime}$ & 1.4280 & M.S. \\
\hline
\end{tabular}


Here also for $4 \mathrm{~mm}$. thickness plate for different weld cross-section angular is different. Higher the weld metal deposition greater the angular distortion. Higher the weld section greater the angular distortion. Higher the heat input greater the angular distortion. Distortion is highest at the weld line lowest or zero at the end of the plates. The angular distortion lies between $0^{0} 59^{\prime} 53^{\prime \prime}$ to $1^{0} 58^{\prime} 53^{\prime \prime}$ for above specified weld crosssection.

For $5 \mathrm{~mm}$. thickness plates three types of weld sections has been taken and they are $60^{\circ}, 90^{\circ}$ and $120^{\circ}$ vee angles. Using the Table's and following the exact method of calculating distortion of various points, the graphs are drawn and shown in graph

5.7 to graph 5.12. It is found that for same thickness higher the weld cross-section area greater the angular distortion.

Table - 5.3 Table of Average angular distortion in plates of thickness 5mm

\begin{tabular}{|c|c|c|c|c|c|c|}
\hline Job & Plate & Weld & \multicolumn{2}{|l|}{ Average } & Deflection & Material \\
\hline No. & thickness & section in & \multicolumn{2}{|l|}{ angular } & in $\mathrm{Y} \mathrm{mm}$. & (Mild \\
\hline & in $\mathrm{mm}$. & degree & \multicolumn{2}{|c|}{ distortion } & & steel or \\
\hline & & & \multicolumn{2}{|l|}{$\left(2 \theta^{0}\right)$} & & EN-31) \\
\hline & & & {$\left[\theta^{0}=\left(\theta_{1}\right.\right.$} & $\left.{ }^{0}+\boldsymbol{\theta}_{2}{ }^{0}\right)$ & & \\
\hline & & & $/ 2]$ & & & \\
\hline $\mathbf{W}_{4}$ & 5 & $60^{0}$ & \multicolumn{2}{|l|}{$1^{0} 33^{\prime} 26^{\prime \prime}$} & 2.1757 & EN-31 \\
\hline $\mathbf{W}_{5}$ & 5 & $90^{\circ}$ & \multicolumn{2}{|l|}{$1^{0} 04^{\prime} 32^{\prime \prime}$} & 1.9727 & EN-31 \\
\hline $\mathrm{W}_{6}$ & 5 & $120^{\circ}$ & \multicolumn{2}{|l|}{$1^{0} 1328$} & 1.6661 & EN-31 \\
\hline W13 & 5 & $60^{\circ}$ & \multicolumn{2}{|l|}{$2^{0} 05^{\prime} 13^{\prime \prime}$} & 1.6883 & M.S. \\
\hline W14 & 5 & $90^{\circ}$ & \multicolumn{2}{|l|}{$2^{0} 54^{\prime} 19^{\prime \prime}$} & 2.6469 & M.S. \\
\hline W15 & 5 & $120^{\circ}$ & \multicolumn{2}{|l|}{$2^{0} 1328$} & 1.8964 & M.S. \\
\hline
\end{tabular}

The angular distortion lies between $1^{0} 04^{\prime} 32^{\prime \prime}$ to $2^{0} 54^{\prime} 19^{\prime \prime}$ for plates $\mathrm{W}_{4}, \mathrm{~W}_{5}$,

$\mathrm{W}_{6}, \mathrm{~W}_{13}, \mathrm{~W}_{14}$ and $\mathrm{W}_{15}$.(Refer Table 5.3).

Different plate thickness is taken for studying the angular distortion of butt welded plate. The different plate thicknesses are $6 \mathrm{~mm}$., $5 \mathrm{~mm}$. and $4 \mathrm{~mm}$. The angular distortion for different plate thickness is shown in graphs. 5.1 to 5.6. The distortion values are shown in Table 5.1 to 5.3.

Table - 5.4 Table of Average angular distortion in all the plates of EN-31 and M.S.

\begin{tabular}{|c|c|c|c|c|c|c|c|}
\hline SNo & Jb No. & Plate & Weld & \multicolumn{2}{|l|}{ Average } & Def. in & Material \\
\hline & & thickness & sect. & \multicolumn{2}{|l|}{ angular } & Y mm. & (Mild \\
\hline & & in $\mathbf{~ m m}$. & in & \multicolumn{2}{|l|}{ distortion } & & steel or \\
\hline & & & degree & $\left.2 \theta^{0}\right)$ & & & EN-31) \\
\hline & & & & {$\left[\theta^{0}=\left(\theta_{1}\right.\right.$} & ${ }^{0}+\theta_{2}$ & & \\
\hline & & & & $\left.\left.{ }^{0}\right) / 2\right]$ & & & \\
\hline 1. & W1 & 6 & $60^{\circ}$ & $1^{0} 58^{\prime} 53^{\prime \prime}$ & & 2.8211 & EN-31 \\
\hline & & & & & & & \\
\hline 2. & $\mathrm{~W}_{4}$ & 5 & $60^{\circ}$ & $1^{0} 3326$ & & 2.1757 & EN-31 \\
\hline 3. & $\mathrm{~W}_{7}$ & 4 & $60^{0}$ & $0^{0} 59^{\prime} 53^{\prime \prime}$ & & 1.8516 & EN-31 \\
\hline 4. & W10 & 6 & $60^{\circ}$ & $3^{0} 0452$ & & 3.0489 & M.S. \\
\hline & & & & & & & \\
\hline 5. & W13 & 5 & $60^{\circ}$ & $2^{0} 0513$ & & 1.6883 & M.S. \\
\hline 6. & W16 & 4 & $60^{\circ}$ & $1^{0} 54^{\prime} 52^{\prime \prime}$ & & 1.4050 & M.S. \\
\hline 7. & $\mathrm{~W}_{2}$ & 6 & $90^{\circ}$ & $1^{0} 52^{\prime} 38^{\prime \prime}$ & & 2.2889 & EN-31 \\
\hline & & & & & & & \\
\hline 8. & $\mathrm{~W}_{5}$ & 5 & $90^{0}$ & $1^{0} 04^{\prime} 32^{\prime \prime}$ & & 1.9727 & EN-31 \\
\hline 9. & $\mathrm{~W}_{8}$ & 4 & $90^{\circ}$ & $1^{0} 02^{\prime} 29^{\prime \prime}$ & & 1.7817 & EN-31 \\
\hline 10. & W11 & 6 & $90^{\circ}$ & $3^{0} 07^{\prime} 39^{\prime \prime}$ & & 3.4989 & M.S. \\
\hline 11. & W14 & 5 & $90^{0}$ & $2^{0} 54^{\prime} 19^{\prime \prime}$ & & 2.6469 & M.S. \\
\hline
\end{tabular}


Experimental Study of Distortion in Butt Welds of Mild Steel Plates and En-31 Plates Having

\begin{tabular}{|c|c|c|c|c|c|c|}
\hline & & & & & & \\
\hline 12. & W17 & 4 & $90^{\circ}$ & $1^{0} 2956$ & 1.8395 & M.S. \\
\hline 13. & $\mathrm{~W}_{3}$ & 6 & $120^{\circ}$ & $1^{0} 14^{\prime} 23^{\prime \prime}$ & 1.7897 & EN-31 \\
\hline & & & & & & \\
\hline & & & & & & \\
\hline
\end{tabular}

\begin{tabular}{|c|c|c|c|c|c|c|}
\hline 14. & $\mathrm{~W}_{6}$ & 5 & $120^{\circ}$ & $1^{0} 13 \quad 288^{\prime \prime}$ & 1.6661 & EN-31 \\
\hline 15. & W9 & 4 & $120^{\circ}$ & $1^{0} 07^{\prime} 13^{\prime \prime}$ & 1.5675 & EN-31 \\
\hline 16. & W12 & 6 & $120^{\circ}$ & $2^{0} 52^{\prime} 13^{\prime \prime}$ & 2.2130 & M.S. \\
\hline 17. & W15 & 5 & $120^{\circ}$ & $2^{0} 13^{\prime} 28^{\prime \prime}$ & 1.8964 & M.S. \\
\hline 18. & W18 & 4 & $120^{\circ}$ & $1^{0} 58^{\prime} 53^{\prime \prime}$ & 1.4280 & M.S. \\
\hline
\end{tabular}

Here the jobs of several plate thicknesses verses average angular distortion are shown in Table No. 5.4. From this table it is observed that for plate thickness $6 \mathrm{~mm}$. $5 \mathrm{~mm}$, and $4 \mathrm{~mm}$. of same weld cross-section of $60^{\circ}$ vee the average angular distortion are $1^{0} 58^{\prime} 53^{\prime \prime}, 1^{0} 33^{\prime} 26^{\prime \prime}$ and $0^{\circ} 59^{\prime} 53^{\prime \prime}$ and y-deflection's are 3.4989 $\mathrm{mm}$., $2.6469 \mathrm{~mm} ., 1.8516 \mathrm{~mm}$ respectively for EN-31 plates and $3^{0} 04^{\prime} 52^{\prime \prime}, 2^{0} 05^{\prime} 13^{\prime \prime}$ and $1^{0} 54^{\prime} 52^{\prime \prime}$. ydeflections are $3.0489 \mathrm{~mm}$. , $1.6883 \mathrm{~mm}$. $1.4050 \mathrm{~mm}$. respectively for mild steel plates. This shows that the average angular distortion decreases as the plate thickness decreases and vice-versa. This result is shown in graph 5.19 to 5.21

Similar procedure is obtained for $90^{\circ}$ vee of butt welded plate for above mentioned thickness of plates.

The average angular distortion are $1^{0} 52^{\prime} 38^{\prime \prime}, 1^{0} 04^{\prime} 32^{\prime \prime}$ and $1^{0} 02^{\prime} 29^{\prime \prime}$ and y-deflection's are 2.2889 mm., $1.9727 \mathrm{~mm}$., $1.7817 \mathrm{~mm}$ respectively for EN-31 plates and $3^{0} 07^{\prime} 39^{\prime \prime}, 2^{0} 54^{\prime} 19^{\prime \prime}$ and $1^{0} 29^{\prime} 56^{\prime \prime}$. $\mathrm{y}$ deflections are $3.0489 \mathrm{~mm} ., 1.6883 \mathrm{~mm} .1 .8395 \mathrm{~mm}$. respectively for mild steel plates. This shows that the average angular distortion decreases as the plate thickness decreases and vice-versa and mild steel plates has more distorted comparison that EN-31 plates. More-over all the average angular distortion is shown in a graph no.5.1 to 5.6. Comparison of EN-31 plates and Mild Steel plates of average angular distortion shown in graph 5.19 to graph 5.21, average longitudinal shrinkage is shown in graph 5.22 to graph 5.24 and average transverse shrinkage is shown in figure 5.25 to 5.27

\subsection{Measurement of distortion due to transverse shrinkage}

The values obtained for transverse shrinkage are given below in Table No. 5.5 for all the jobs i.e. $\mathrm{W}_{1}, \mathrm{~W}_{2}, \mathrm{~W}_{3}$ $\mathrm{W}_{4}, \mathrm{~W}_{5}, \mathrm{~W}_{6}, \mathrm{~W}_{7}, \mathrm{~W}_{8}, \mathrm{~W}_{9}, \mathrm{~W}_{10}, \mathrm{~W}_{11}, \mathrm{~W}_{12}, \mathrm{~W}_{13}$,

$\mathrm{W} 14, \mathrm{~W} 15, \mathrm{~W} 16, \mathrm{~W} 17$ \& W18.

Table - 5.5 Table of Average Transverse Shrinkage in plates of EN-31 and M.S. of various cross-sections.

\begin{tabular}{|c|c|c|c|c|c|}
\hline Serial & Job & Plate & Weld & Average & Material (Mild \\
\hline No. & No. & thickness & section & transverse & steel or EN-31) \\
\hline & & in $\mathrm{mm}$. & in & shrinkage in & \\
\hline & & & degree & $\mathbf{m m}$. & \\
\hline 1. & $\mathrm{~W}_{1}$ & 6 & $60^{\circ}$ & 0.99 & EN-31 \\
\hline 2. & $\mathrm{~W}_{4}$ & 5 & $60^{0}$ & 0.73 & EN-31 \\
\hline 3. & $\mathrm{~W}_{7}$ & 4 & $60^{\circ}$ & 0.47 & EN-31 \\
\hline 4. & W10 & 6 & $60^{0}$ & 0.78 & M.S. \\
\hline 5. & W13 & 5 & $60^{0}$ & 0.48 & M.S. \\
\hline 6. & W16 & 4 & $60^{0}$ & 0.37 & M.S. \\
\hline 7. & $\mathrm{~W}_{2}$ & 6 & $90^{\circ}$ & 1.33 & EN-31 \\
\hline 8. & $\mathrm{~W}_{5}$ & 5 & $90^{\circ}$ & 0.80 & EN-31 \\
\hline 9. & $\mathrm{~W}_{8}$ & 4 & $90^{\circ}$ & 0.71 & EN-31 \\
\hline 10. & W11 & 6 & $90^{\circ}$ & 0.91 & M.S. \\
\hline 11. & W14 & 5 & $90^{\circ}$ & 0.83 & M.S. \\
\hline 12. & W17 & 4 & $90^{\circ}$ & 0.86 & M.S. \\
\hline 13. & $\mathrm{~W}_{3}$ & 6 & $120^{\circ}$ & 1.80 & EN-31 \\
\hline 14. & $\mathrm{~W}_{6}$ & 5 & $120^{\circ}$ & 1.36 & EN-31 \\
\hline 15. & W9 & 4 & $120^{\circ}$ & 1.13 & EN-31 \\
\hline
\end{tabular}




\begin{tabular}{|l|l|l|l|l|l|}
\hline & & & & & \\
\hline 16. & W12 & 6 & $120^{0}$ & 1.63 & M.S. \\
\hline & & & & & \\
\hline 17. & W15 & 5 & $120^{0}$ & 1.45 & M.S. \\
\hline & & & & & \\
\hline 18. & W18 & 4 & $120^{0}$ & 1.69 & M.S. \\
\hline & & & & & \\
\hline
\end{tabular}

From the above table it has been found that the transverse shrinkage is dependent on plate thickness and weld cross-section. For higher the thickness of the plate greater is the transverse shrinkage as obtained from experiment. It can also be said that higher the heat input greater is the transverse shrinkage or vice-versa. Higher the weld section of the butt joint greater is the transverse shrinkage and mild steel plates have more transverse shrinkage comparison that EN-31 plates. The transverse shrinkage are shown in graph 5.13 to graph 5.18.

\subsection{Measurement of distortion due to longitudinal shrinkage}

The values obtained for longitudinal shrinkage are given below in Table No. 5.6 for all the jobs (i.e. $\mathrm{W}_{1}$ to $\mathrm{W}_{18}$ ).

Table - 5.6 Table of Average Longitudinal Shrinkage in plates of EN-31 and M.S. of various cross-sections.

\begin{tabular}{|c|c|c|c|c|c|}
\hline Serial & Job & Plate & Weld & Average & Material (Mild \\
\hline No. & No. & thickness & section & longitudinal & steel or EN-31) \\
\hline & & in $\mathbf{~ m m}$. & in & shrinkage in & \\
\hline & & & degree & $\mathbf{m m}$ & \\
\hline 1. & $\mathrm{~W}_{1}$ & 6 & $60^{0}$ & 1.01 & EN-31 \\
\hline 2. & $\mathrm{~W}_{4}$ & 5 & $60^{\circ}$ & 0.63 & EN-31 \\
\hline 3. & $\mathrm{~W}_{7}$ & 4 & $60^{\circ}$ & 0.69 & EN-31 \\
\hline 4. & W10 & 6 & $60^{0}$ & 0.89 & M.S. \\
\hline 5. & W13 & 5 & $60^{\circ}$ & 0.73 & M.S. \\
\hline 6. & W16 & 4 & $60^{\circ}$ & 0.41 & M.S. \\
\hline 7. & $\mathrm{~W}_{2}$ & 6 & $90^{\circ}$ & 149 & FN-31 \\
\hline 8. & $\mathrm{~W}_{5}$ & 5 & $90^{\circ}$ & 1.12 & EN-31 \\
\hline 9. & $\mathrm{~W}_{8}$ & 4 & $90^{\circ}$ & 1.09 & EN-31 \\
\hline 10. & W11 & 6 & $90^{\circ}$ & 1.17 & M.S. \\
\hline 11. & W14 & 5 & $90^{\circ}$ & 1.07 & M.S. \\
\hline 12. & W17 & 4 & $90^{\circ}$ & 0.96 & M.S. \\
\hline 13. & $\mathrm{~W}_{3}$ & 6 & $120^{0}$ & 1.91 & EN-31 \\
\hline 14. & $\mathrm{~W}_{6}$ & 5 & $120^{\circ}$ & 1.74 & EN-31 \\
\hline 15. & $\mathrm{~W}_{9}$ & 4 & $120^{\circ}$ & 1.17 & EN-31 \\
\hline 16. & W12 & 6 & $120^{\circ}$ & 1.83 & M.S. \\
\hline 17. & W15 & 5 & $120^{\circ}$ & 1.67 & M.S. \\
\hline 18. & W18 & 4 & $120^{\circ}$ & 1.68 & M.S. \\
\hline & & & & & \\
\hline
\end{tabular}

From the above table it has been noted that the longitudinal shrinkage is dependent on plate the weld section. For higher longitudinal shrinkage the plate thickness greater. Longitudinal shrinkage for above jobs shown in graph 5.7 to graph 5.12 .

\subsection{Graphs}

Graph 5.1 to graph 5.6 shows average angular distortion of both EN-31 and Mild Steel plates of $4 \mathrm{~mm}, 5 \mathrm{~mm}$, $6 \mathrm{~mm}$ thickness and $60^{\circ}, 90^{\circ}, 120^{\circ}$ cross sections.

Graph 5.7 to graph 5.12 shows average longitudinal shrinkage of both EN-31 and Mild Steel plates of $4 \mathrm{~mm}$, $5 \mathrm{~mm}, 6 \mathrm{~mm}$ thickness and $60^{\circ}, 90^{\circ}, 120^{\circ}$ cross sections.

Graph 5.13 to graph 5.18 shows average transverse shrinkage of both EN-31 and Mild Steel plates of $4 \mathrm{~mm}$, $5 \mathrm{~mm}, 6 \mathrm{~mm}$ thickness and $60^{\circ}, 90^{\circ}, 120^{\circ}$ cross sections.

Graph 5.19 to graph 5.21 shows comparison of average angular distortion in both EN-31 and Mild Steel plates of $4 \mathrm{~mm}, 5 \mathrm{~mm}, 6 \mathrm{~mm}$ thickness and $60^{\circ}, 90^{\circ}, 120^{\circ}$ cross sections. 
Graph 5.19 to graph 5.21 shows comparison of average longitudinal shrinkage in both EN-31 and Mild Steel plates of $4 \mathrm{~mm}, 5 \mathrm{~mm}, 6 \mathrm{~mm}$ thickness and $60^{\circ}, 90^{\circ}, 120^{\circ}$ cross sections.

Graph 5.19 to graph 5.21 shows comparison of average transverse shrinkage in both EN-31 and Mild Steel plates of $4 \mathrm{~mm}, 5 \mathrm{~mm}, 6 \mathrm{~mm}$ thickness and $60^{\circ}, 90^{\circ}, 120^{\circ}$ cross sections.

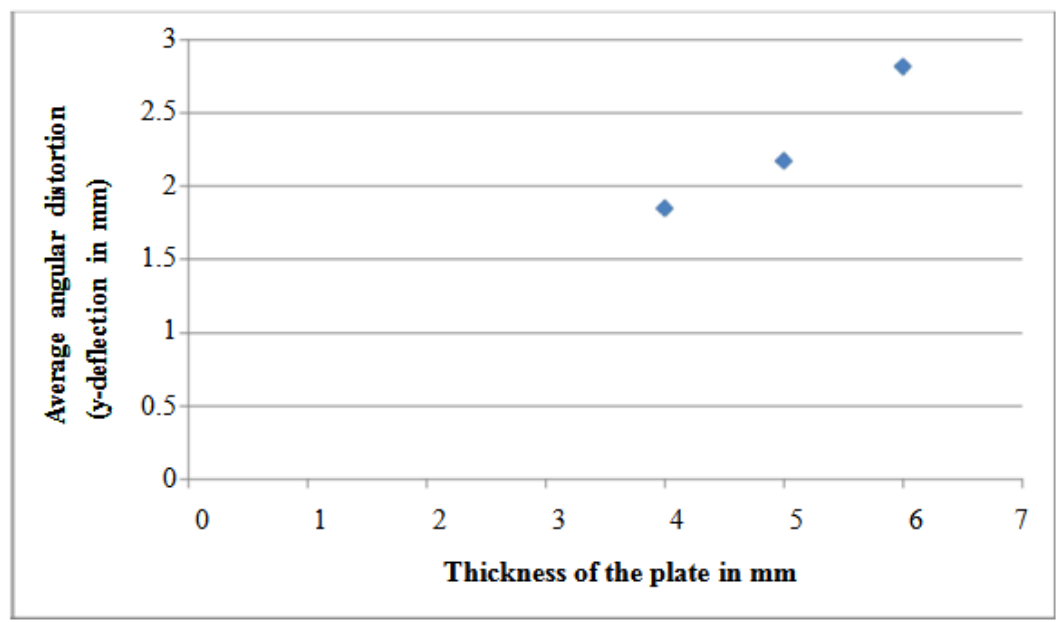

Graph 5.1 Graph of Average angular distortion of $60^{\circ}$ cross-section angle of EN-31 plate

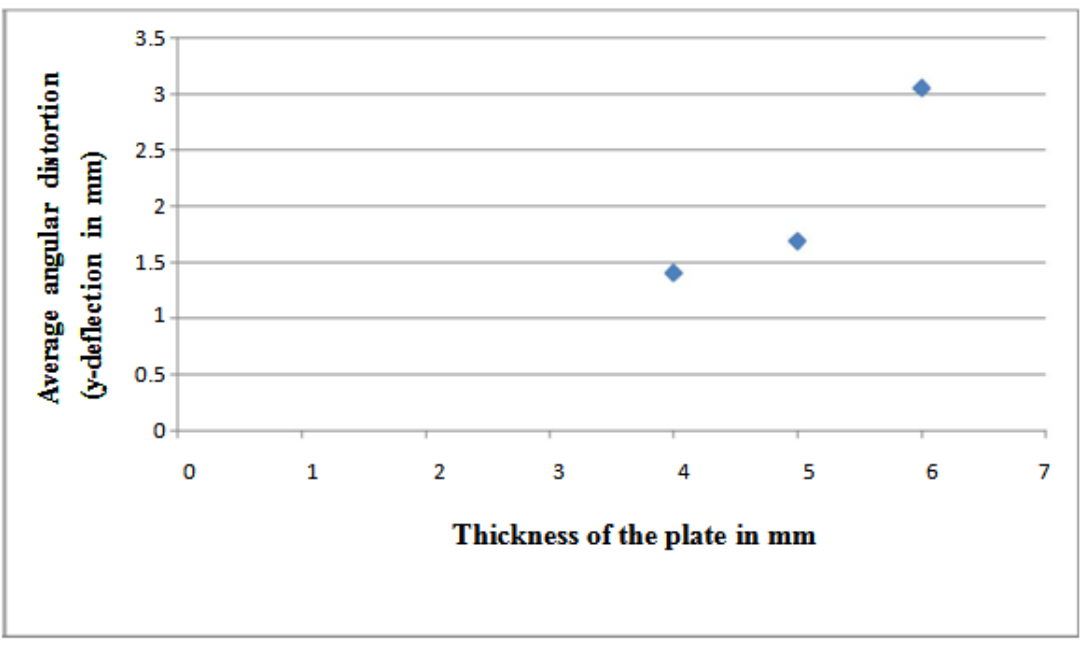

Graph 5.2 Graph of Average angular distortion of $60^{\circ}$ cross-section angle of M.S. plate

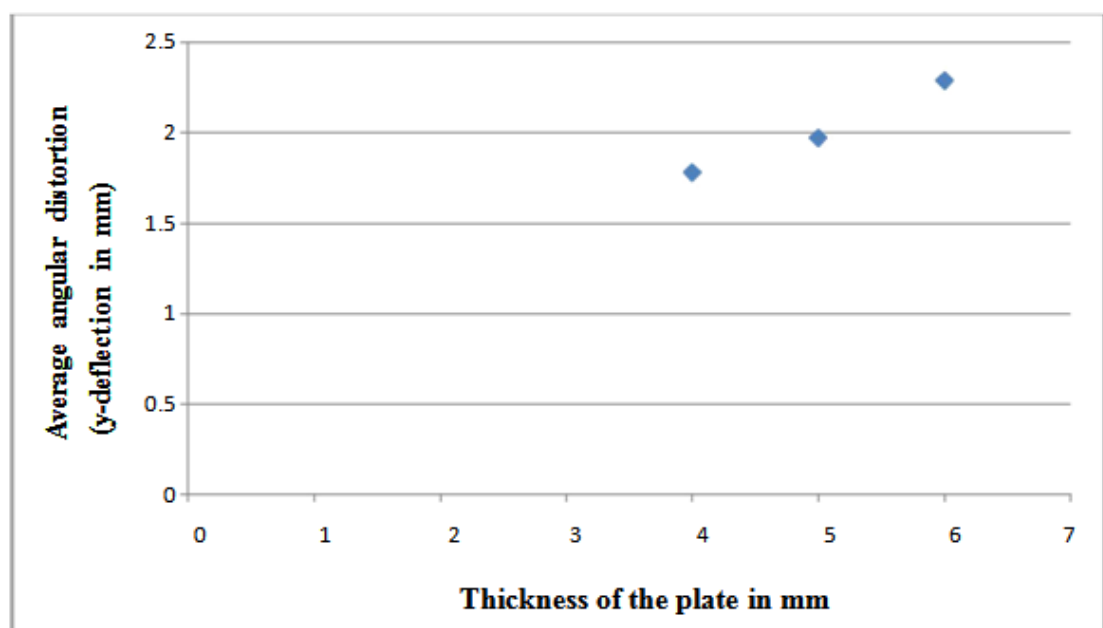

Graph 5.3 Graph of Average angular distortion of $90^{\circ}$ cross-section angle of EN-31 plate 


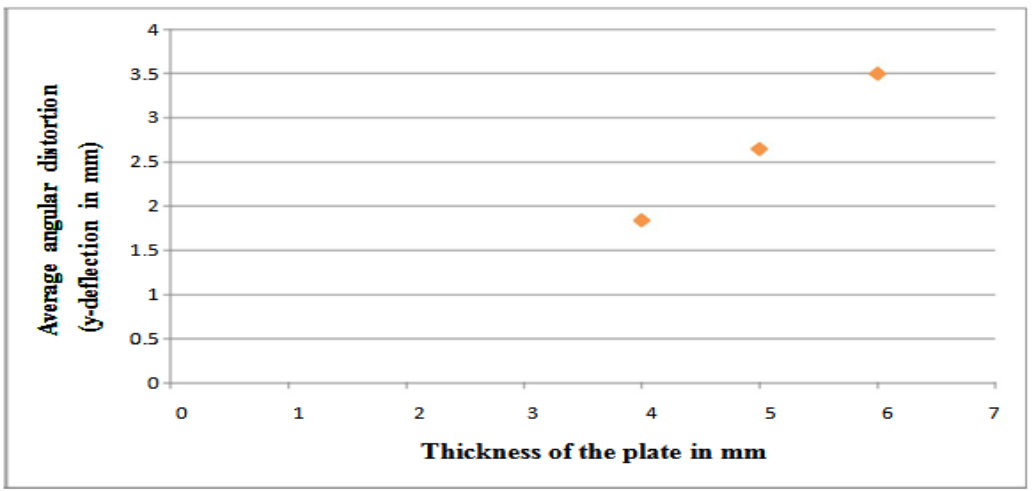

Graph 5.4 Graph of Average angular distortion $90^{\circ}$ cross-section angle of M.S. plate

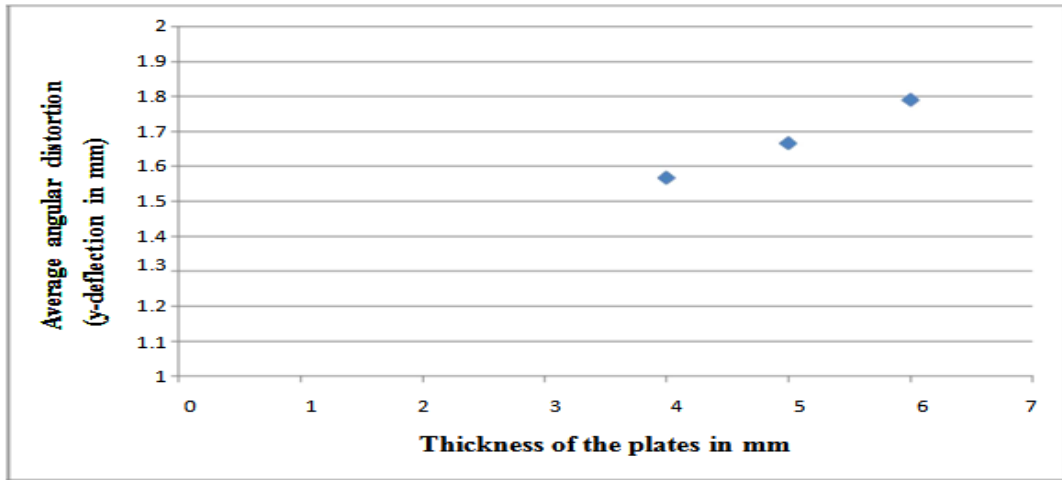

Graph 5.5 Graph of Average angular distortion of $120^{\circ}$ cross-section angle of EN-31 plate

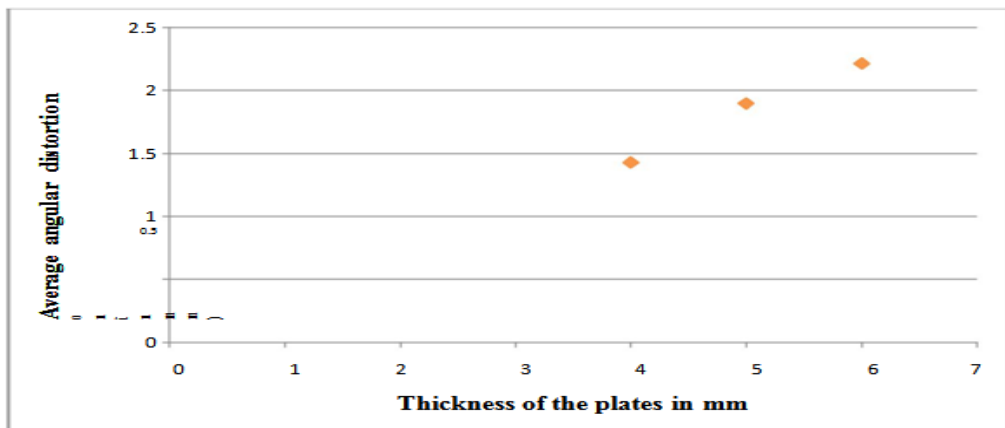

Graph 5.6 Graph of Average angular distortion $120^{\circ}$ cross-section angle of M.S. plate

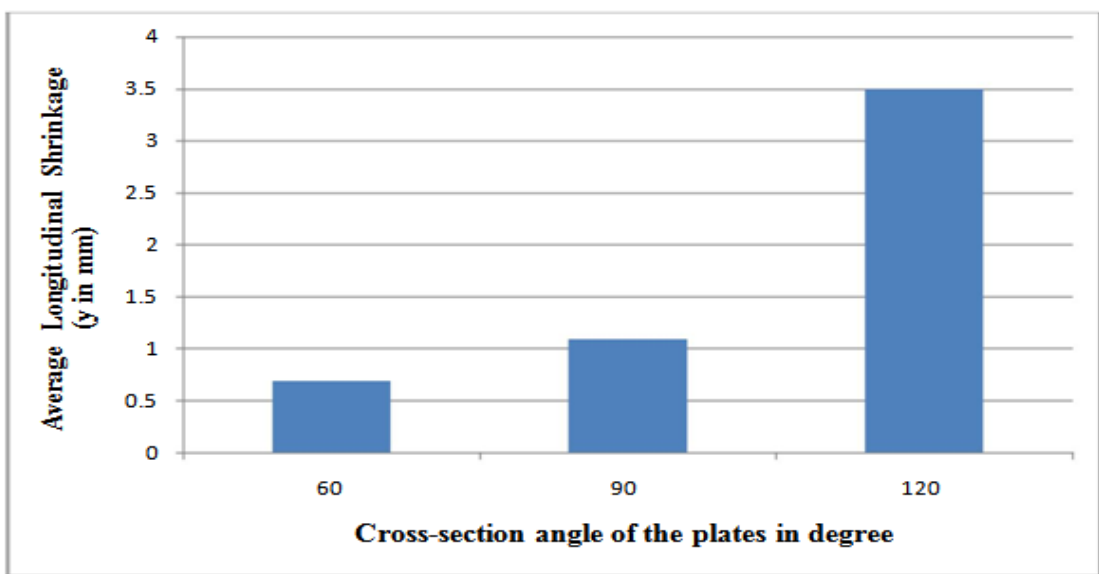

Graph 5.7 Graph of Average longitudinal shrinkage of 4mm.thickness plate of EN-31 


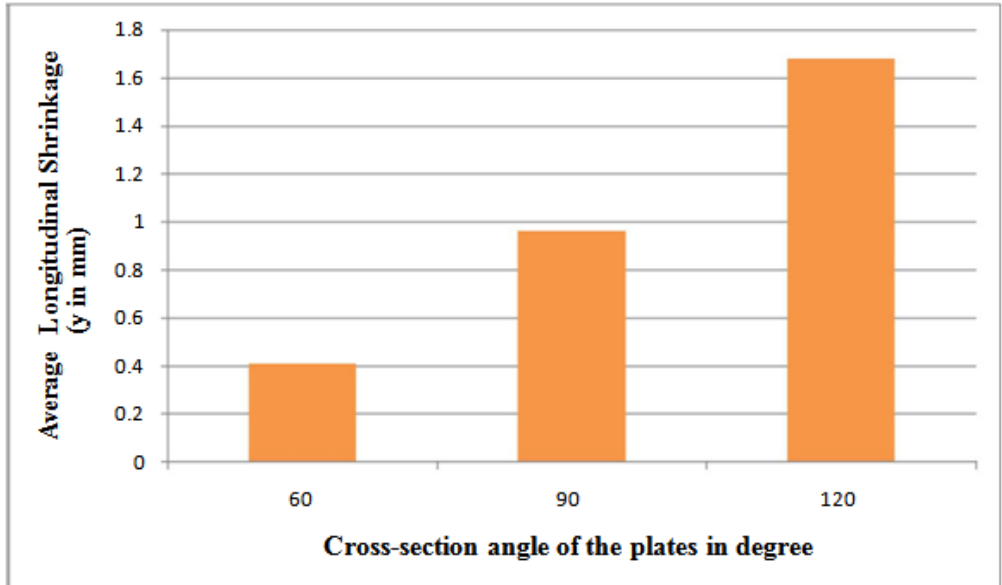

Graph 5.8 Graph of Average longitudinal shrinkage of 4mm.thickness plate of Mild Steel

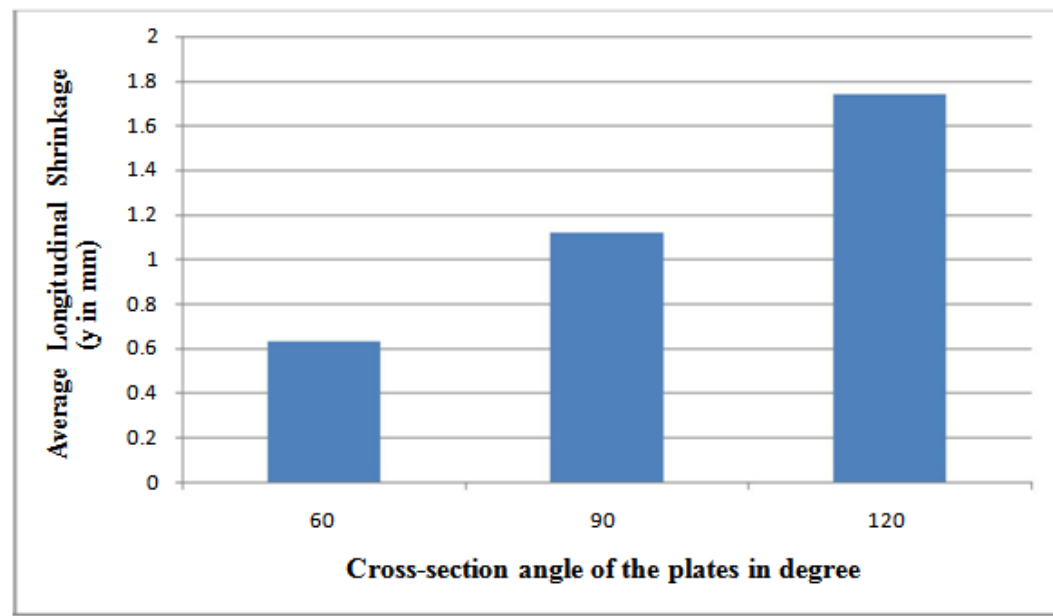

Graph 5.9 Graph of Average longitudinal shrinkage of 5mm.thickness plate of EN-31

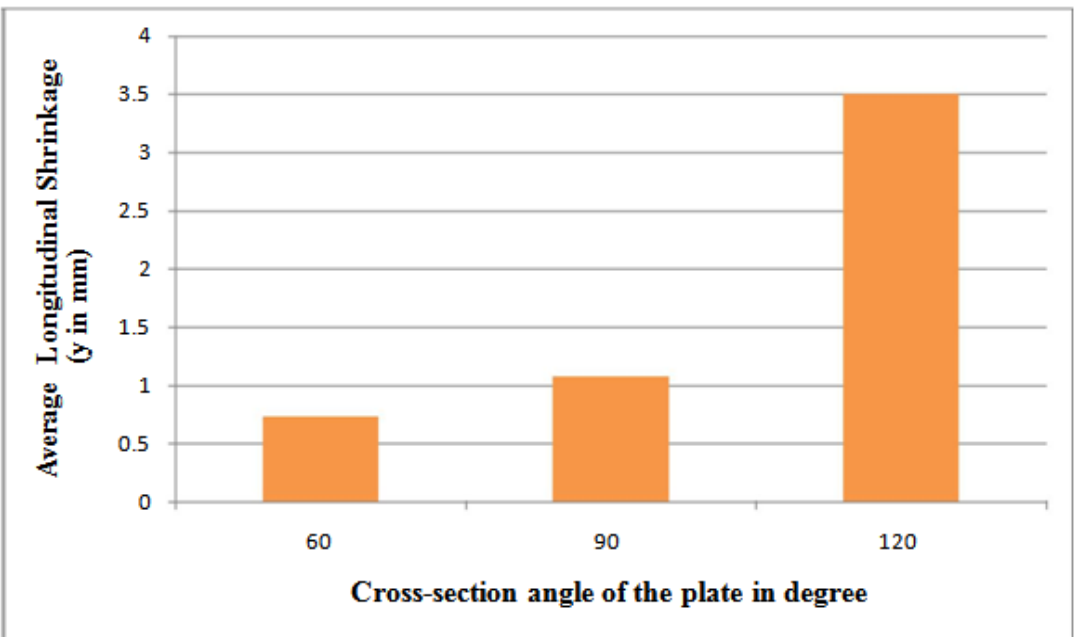

Graph 5.10 Graph of Average longitudinal shrinkage of $5 \mathrm{~mm}$.thickness plate of M.S 


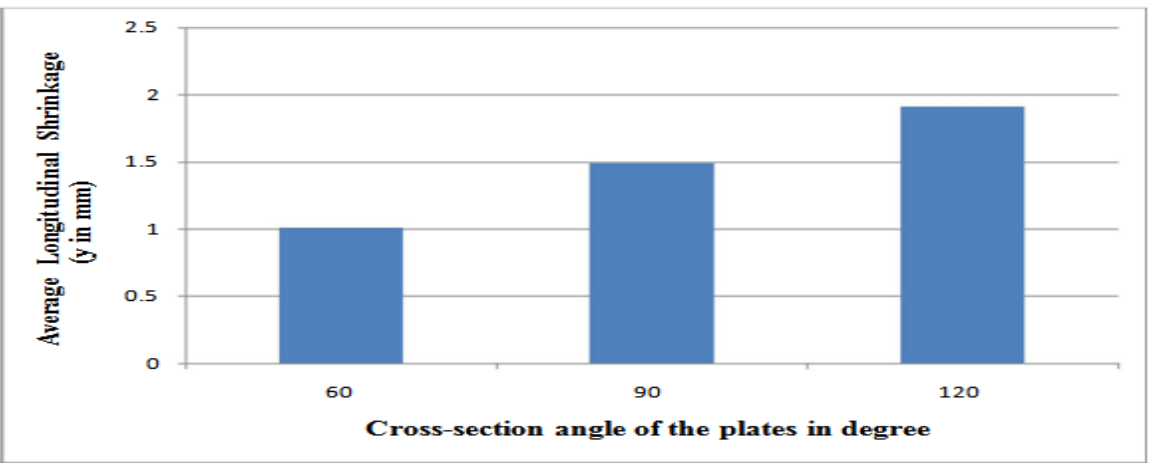

Graph 5.11 Graph of Average longitudinal shrinkage of $6 \mathrm{~mm}$.thickness plate of EN-31

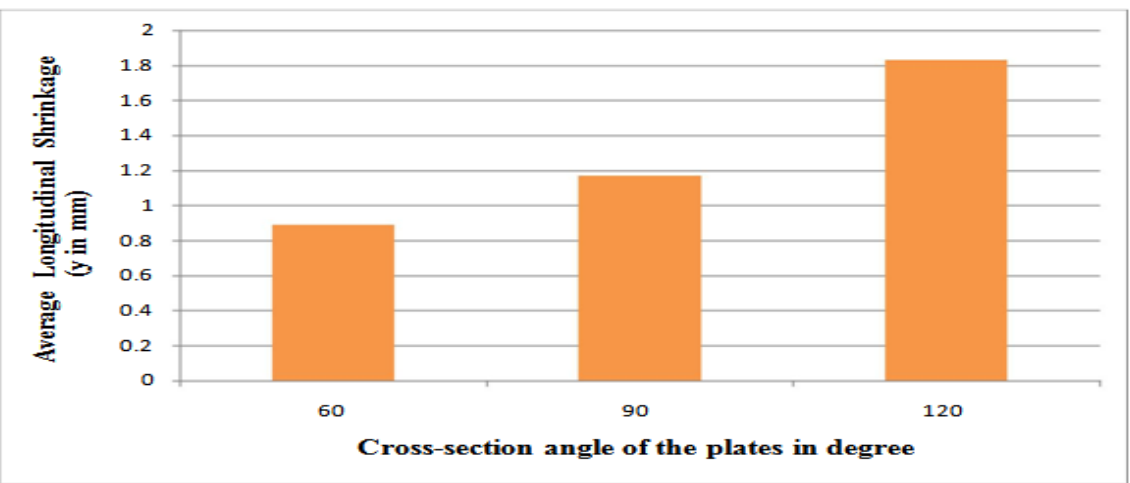

Graph 5.12 Graph of Average longitudinal shrinkage of $6 \mathrm{~mm}$.thickness plate of M.S.

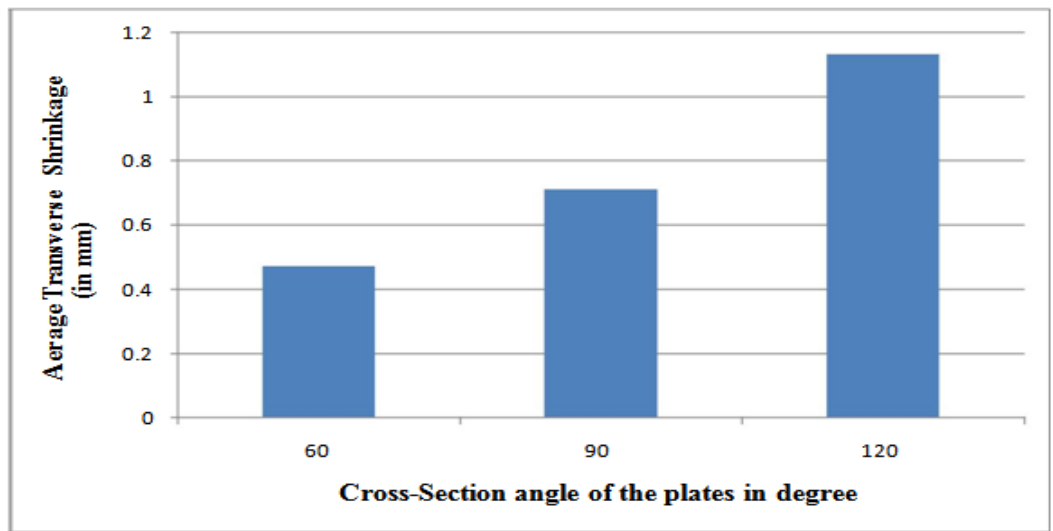

Graph 5.13 Graph of Average transverse shrinkage of 4mm.thickness plate of EN-31

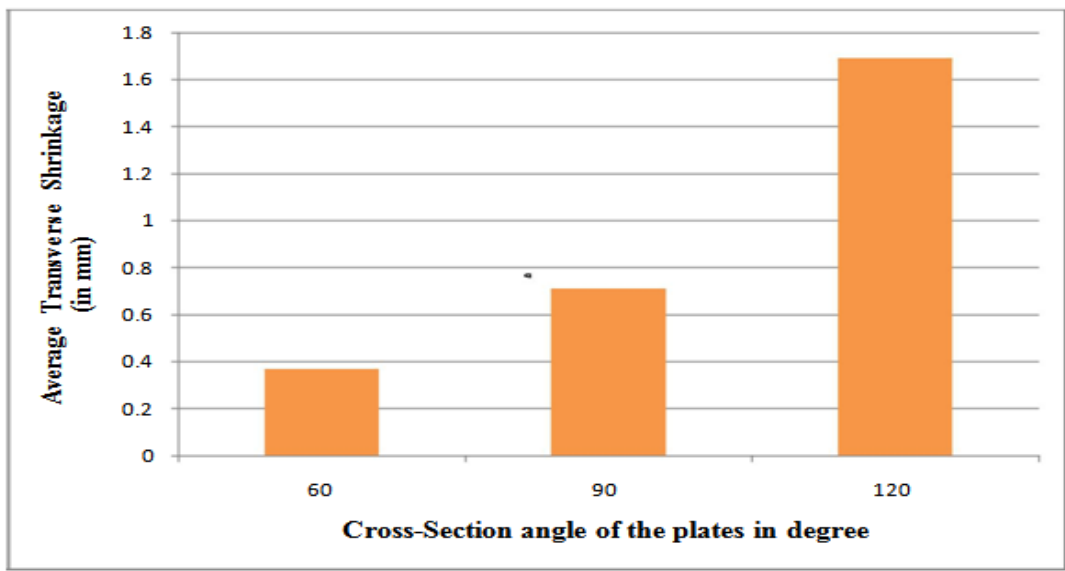

Graph 5.14 Graph of Average transverse shrinkage of 4mm.thickness plate of M.S. 




Graph 5.15 Graph of Average transverse shrinkage of 5mm.thickness plate of EN-31

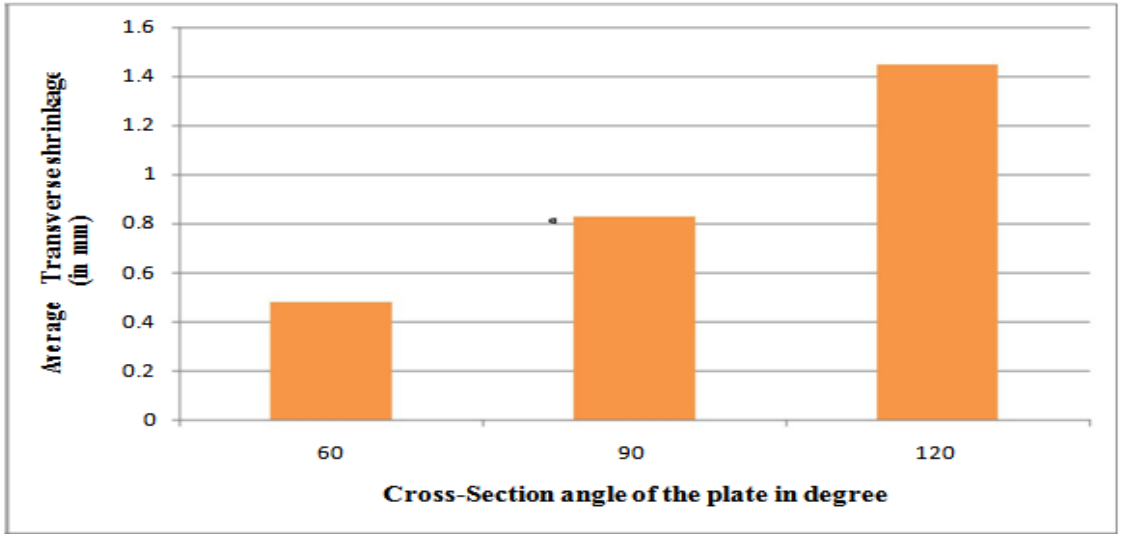

Graph 5.16 Graph of Average transverse shrinkage of 5mm thickness plate of M.S.

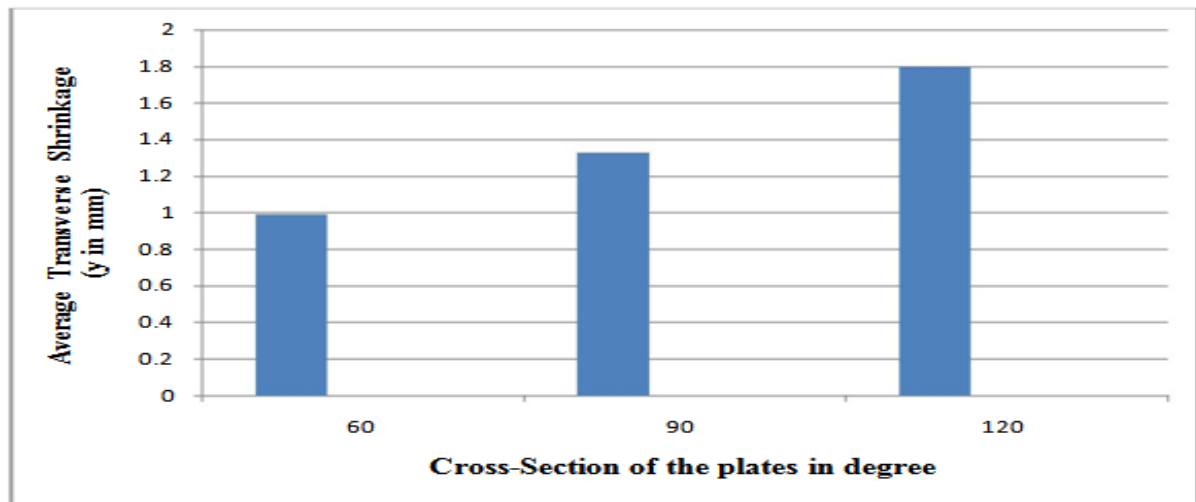

Graph 5.17 Graph of Average transverse shrinkage of 6mm.thickness plate of EN-31

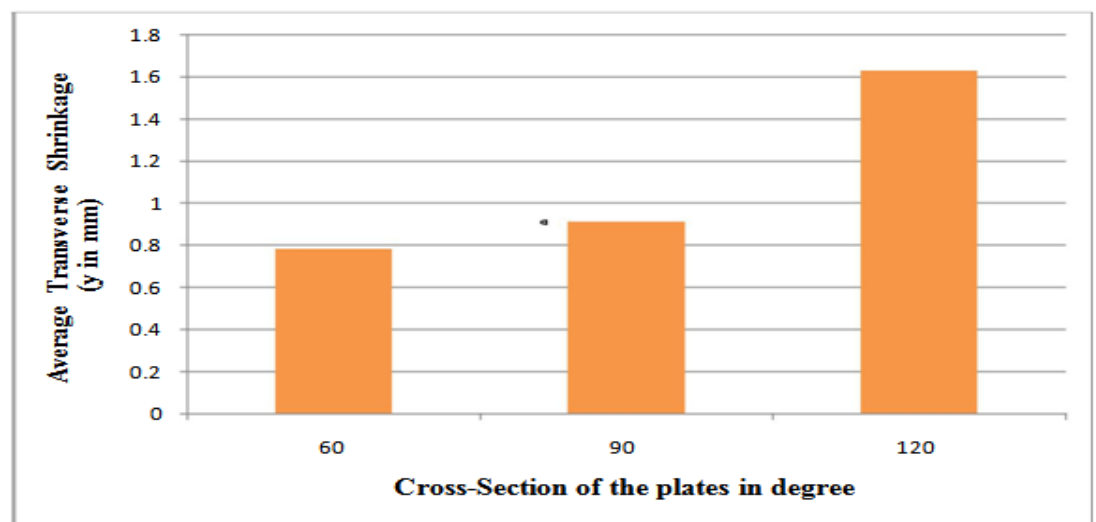

Graph 4.18 Graph of Average transverse shrinkage of $6 \mathrm{~mm}$.thickness plate of M.S. 


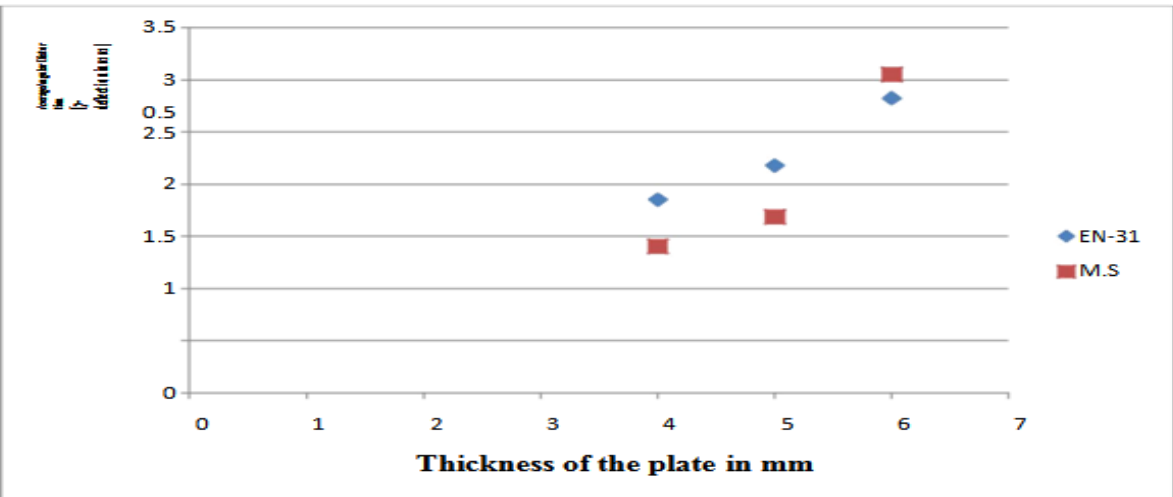

Graph 5.19 Graph of Average angular distortion $60^{\circ}$ cross-section angle of EN-31 and M.S. plate

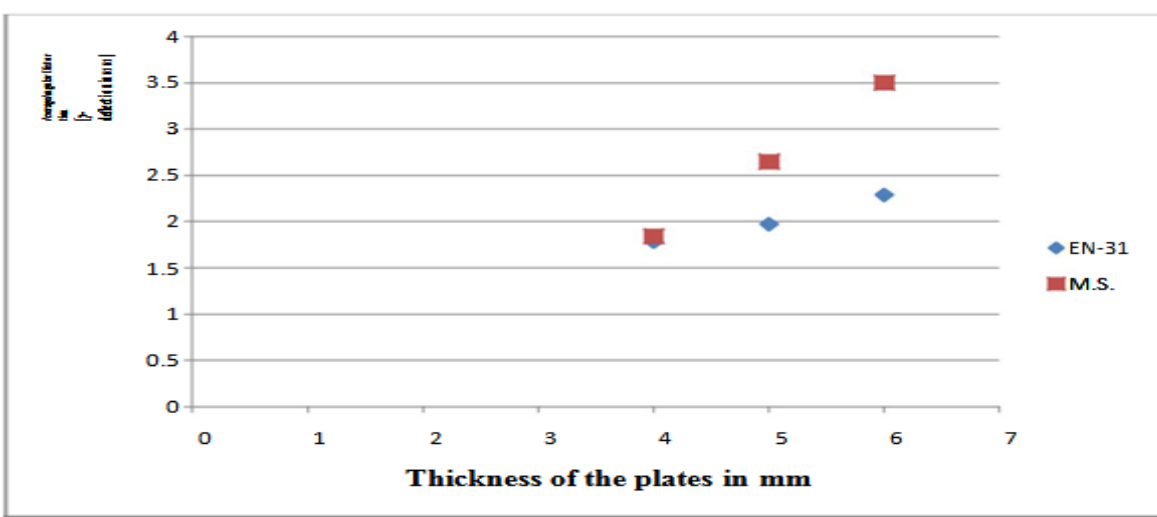

Graph 5.20 Graph of Average angular distortion $90^{\circ}$ cross-section angle of EN-31 and M.S. plate



Graph 5.21 Graph of Average angular distortion $120^{\circ}$ cross-section angle of EN-31 and M.S. plate

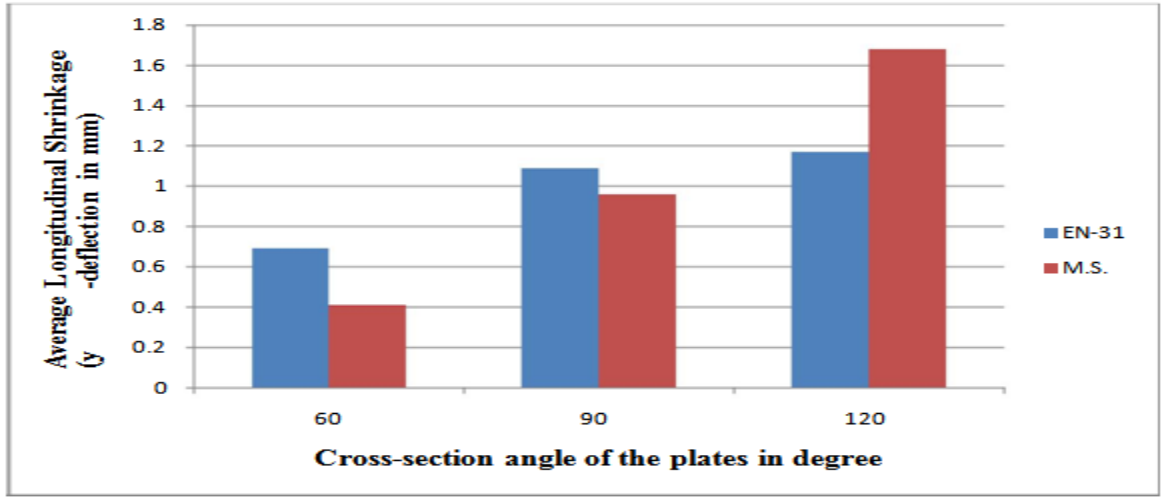

Graph 5.22 Graph of Average longitudinal shrinkage of 4mm.thickness plate of EN-31 and M.S 


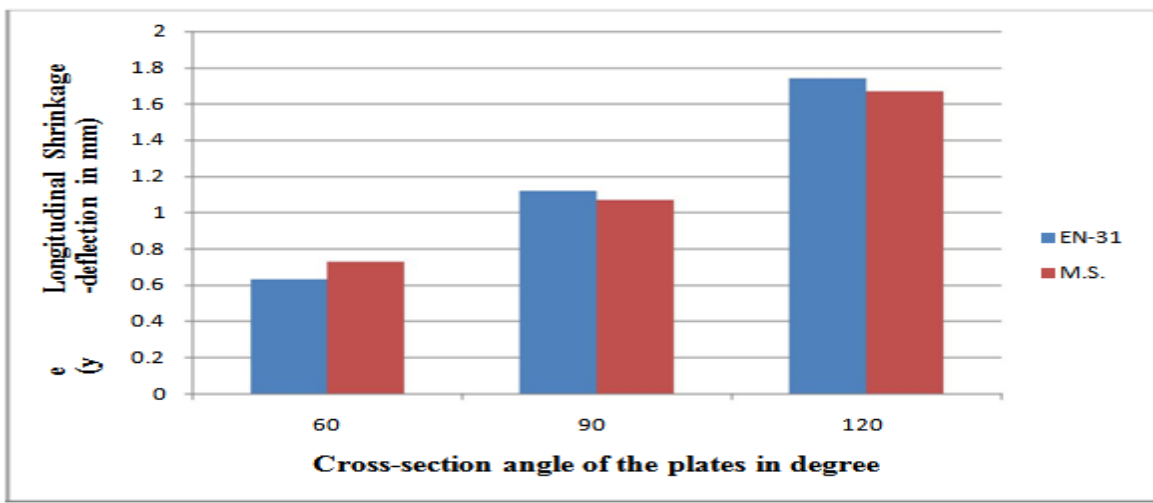

Graph 5.23 Graph of Average longitudinal shrinkage of 5mm.thickness plate of EN-31 and M.S

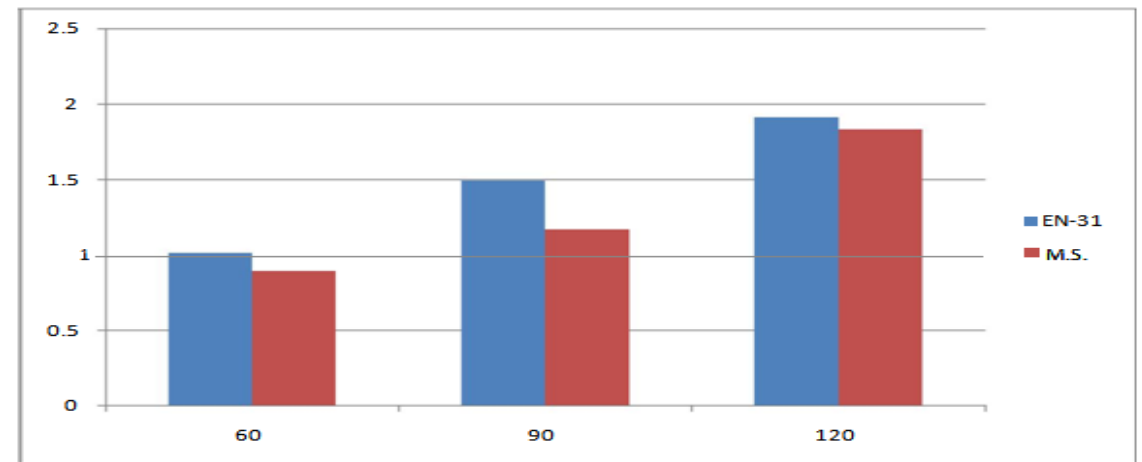

Graph 5.24 Graph of Average longitudinal shrinkage of 6mm.thickness plate of EN-31 and M.S

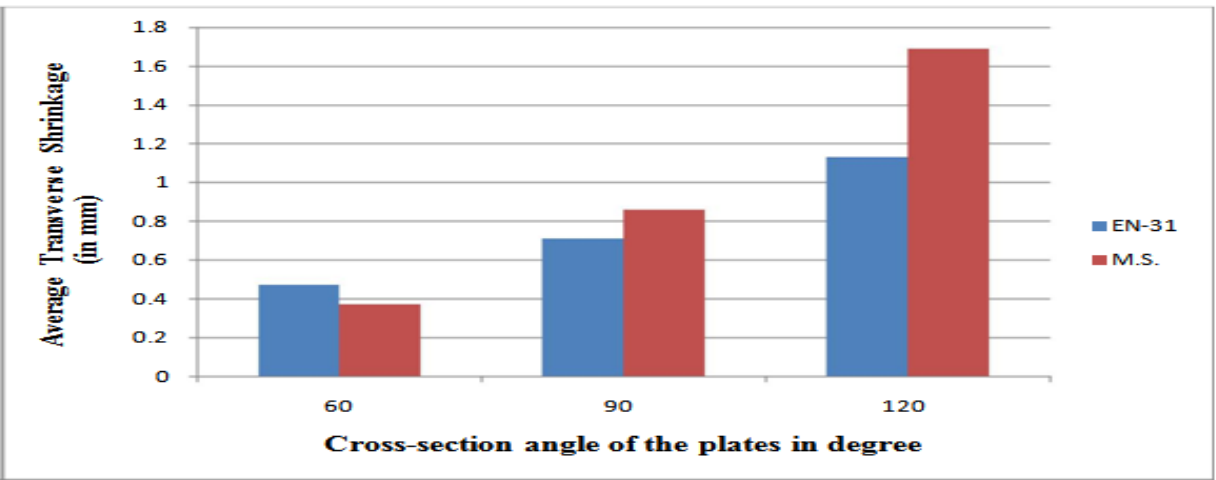

Graph 5.25 Graph of Average transverse shrinkage of 4mm.thickness plates of EN-31 and M.S.

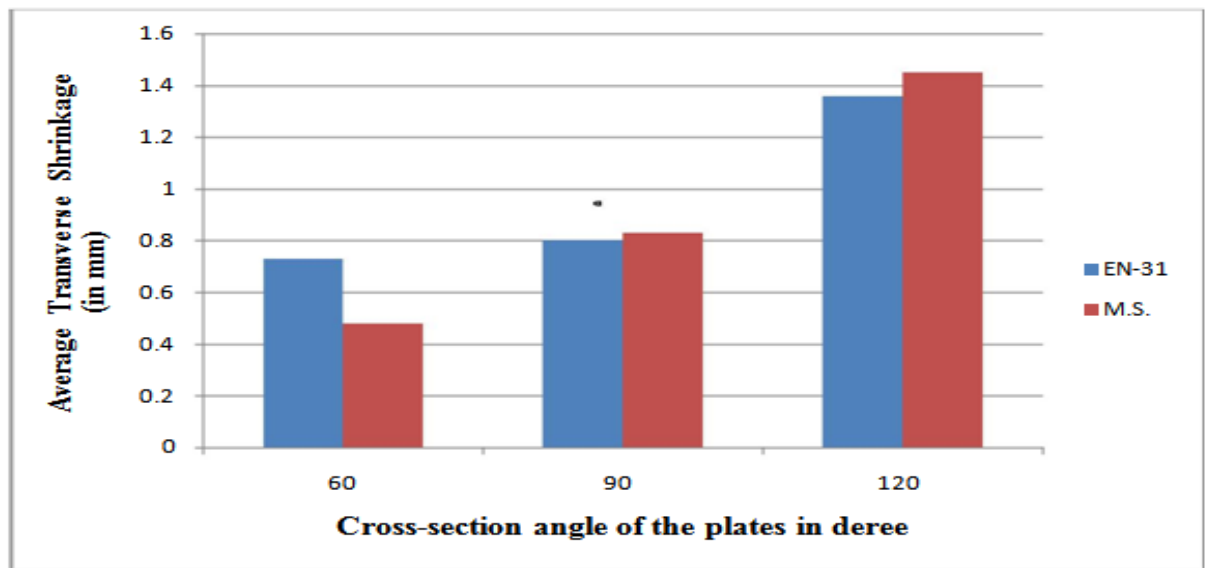

Graph 5.26 Graph of Average transverse shrinkage of 5mm.thickness plates of EN-31 and M.S. 




Graph 5.27 Graph of Average transverse shrinkage of 6mm.thickness plates of EN-31 and M.S.

\section{Conclusion}

Distortion is must when a plate is welded with another one. The amount of distortion can be controlled or minimize if pre-setting techniques are apply through welding fixtures. By controlling the distortion or fabricated works lot of manufacturing cost can be saved. So prediction of distortion before welding is of great importance for the setting techniques. The present project work can give the prediction of distortion. It has been found out the limit of angular distortion for three types of design for different thickness of plates i.e. $6 \mathrm{~mm}, 5$ $\mathrm{mm}$ and $4 \mathrm{~mm}$. with $120^{\circ}, 90^{\circ}$, and $60^{\circ} \mathrm{Vee}$. These values of distortion will help the welder before welding to the present job and hence minimize distortion. But, still there is lack of information of this study. It can't be suggested that what will happen if different types of weld cross section, different types of plate thickness, and different types of plate material are used in butt welding joints. Hence further study is necessary. Moreover it can't be said that what will happen if the other parameters of welding like speed of welding, voltage of welding, time of welding etc. which were kept constant in this study work. Hence scope of further work is still left wide open.

\section{References}

[1] C. L. Tsai, S. C. Park and W. T. Cheng, 1999, "Welding Distortion of a Thin-Plate Panel Structure"

[2] T.D. Huang, Pingsha Dong, Lawrence A. DeCan, Dennis D.Harwig, 2003, "Residual stresses and Distortions in Light weight ship panel structures".

[3] V. VEL MURUGAN AND V. GUNARAJ, 2005," Effects of Process Parameters on Angular Distortion of Gas Metal Arc Welded Structural Steel Plates", Sponsored by the American Welding Society and the Welding Research Council

[4] Dean Deng, 2008," FEM prediction of welding residual stress and distortion in carbon steel considering phase transformation effects", Research Centre of Computational Mechanics Inc., Department of Technical Development, Togoshi NI-Building, 1-7-1, Togoshi, Shinagawa-ku,Tokyo 142-0041, Japan.

[5] S.F. Estefen, T. Gurova, X. Castello, A. Leontiev, 2009, "Surface residual stress evaluation in double-electrode butt welded steel plates"

[6] De-An DENG, 2010," Theoretical prediction of welding distortion in large and complex structures", College of Material Science and Engineering, Chongqing University, Chongqing 400045, China.

[7] Panagiotis Michaleris and Andrew DeBiccari, "Prediction of Welding Distortion", Edison Welding Institute Columbus, Ohio.

[8] Dean Deng, Ninshu Ma, Hidekazu Murakawa, 2011, "Finite element analysis of welding distortion in a large thin plate panel structure", Transaction of JWRI, Vol. 40, No.1

[9] B. N. Sathyanarayana Reddy and N. Lakshmana Swamy, 2013, "Influence of Groove Angle in V-groove Butt joints on Transverse shrinkage in CO2 Arc Welding process", Research Scholar, Dept. of Mech. Engg., UVCE, Bangalore University, Bangalore, Karnataka, INDIA, Professor, Dept. of Mech. Engg., UVCE, Bangalore University, Bangalore, Karnataka, INDIA, respectively.

[10] R.R. Chand , I.S. Kim , J.P. Lee, Y.S. Kim , D.G. Kim, 2013, "Numerical and experiment study of residual stress and strain in multi-pass GMA welding".

[11] H.Long, D.Grey, A.Carlier, P.G.Maropoulos, 2014, "Prediction of welding distortion in butt joint of thin plates".Ozaki, Y. Adachi, Y. Iwahori, and N. Ishii, Application of fuzzy theory to writer recognition of Chinese characters, International Journal of Modelling and Simulation, 18(2), 1998, 112-116. (8) 